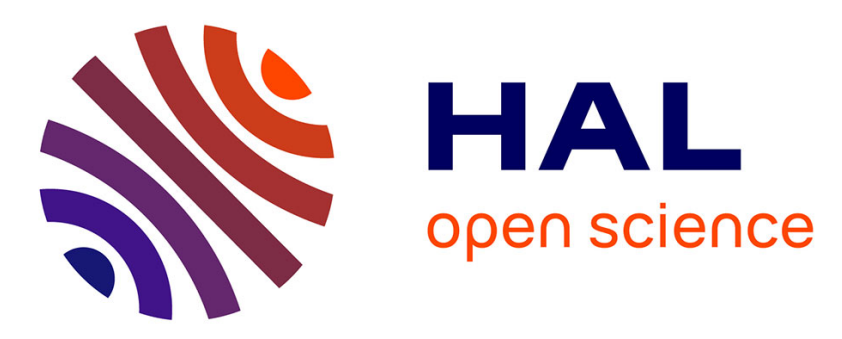

\title{
Multi-scale microstuctural investigation of a new Al-Mn-Ni-Cu-Zr aluminium alloy processed by laser powder bed fusion
}

Maxence Buttard, Béchir Chehab, Ravi Shahani, Florence Robaut, Gilles Renou, Catherine Tassin, Alexis Deschamps, Edgar Rauch, Patricia

Donnadieu, Jean-Jacques Blandin, et al.

\section{To cite this version:}

Maxence Buttard, Béchir Chehab, Ravi Shahani, Florence Robaut, Gilles Renou, et al.. Multi-scale microstuctural investigation of a new Al-Mn-Ni-Cu-Zr aluminium alloy processed by laser powder bed fusion. Materialia, 2021, 18, pp.101160. 10.1016/j.mtla.2021.101160 . hal-03370486

\section{HAL Id: hal-03370486 \\ https://cnrs.hal.science/hal-03370486}

Submitted on 18 Oct 2021

HAL is a multi-disciplinary open access archive for the deposit and dissemination of scientific research documents, whether they are published or not. The documents may come from teaching and research institutions in France or abroad, or from public or private research centers.
L'archive ouverte pluridisciplinaire HAL, est destinée au dépôt et à la diffusion de documents scientifiques de niveau recherche, publiés ou non, émanant des établissements d'enseignement et de recherche français ou étrangers, des laboratoires publics ou privés. 


\title{
Multi-scale microstuctural investigation of a new Al-Mn-Ni-Cu- Zr Al-alloy processed by Laser Powder Bed Fusion
}

\author{
Maxence BUTTARD ${ }^{1}$, Béchir CHEHAB $^{2}$, Ravi SHAHANI ${ }^{2}$, Florence ROBAUT ${ }^{1}$, Gilles RENOU ${ }^{1}$, \\ Catherine TASSIN ${ }^{1}$, Edgar RAUCH ${ }^{1}$, Patricia DONNADIEU ${ }^{1}$, Alexis DESCHAMPS ${ }^{1}$, Jean-Jacques \\ BLANDIN $^{1}$, Guilhem MARTIN ${ }^{1}$ \\ 1. Univ. Grenoble Alpes, CNRS, Grenoble INP, SIMAP, F-38000 Grenoble \\ 2. Constellium Technology Center, Parc économique Centr'Alp, 725, rue Aristide-Bergès, CS 10027, \\ 38341 Voreppe cedex, France
}

\begin{abstract}
Traditional high strength aluminum alloys such as the $2 \mathrm{xxx}$ or $7 \mathrm{xxx}$ series are prone to cracking when processed by additive manufacturing. Designing new aluminum alloys that can be processed crack-free by Laser Powder Bed Fusion (L-PBF) while exhibiting comparable mechanical properties is a major target, which may be reached by including in the alloy design strategy specific features of this processing route such as the very high cooling rates. Here, we study a novel Al-4Mn-3Ni-2Cu-2Zr alloy processed by L-PBF, which shows specific features in comparison to other Al-alloys developed for additive manufacturing. We establish the relationships between the processing conditions and the specific features of the microstructure inherited from L-PBF, using a multi-scale microstructural characterization approach from the melt pool scale up to the nanoscale using X-ray diffraction and electron microscopy with a special focus on Automated Crystal Orientation Mapping (ACOM) in transmission. At the melt pool scale, three regions have been identified: FEZ (Fine Equiaxed Zone), CZ (Columnar Zone) and CEZ (Coarse Equiaxed Zone) giving a hierarchical architecture to the microstructure. Each region has been thoroughly characterized by coupling ACOM and chemical mapping. Five different intermetallic phases have been identified in the as-built microstructure: $\mathrm{Al}_{3} \mathrm{Zr}, \mathrm{Al}_{3} \mathrm{Ni}_{2}, \mathrm{Al}_{9} \mathrm{Ni}_{2}, \mathrm{Al}_{60} \mathrm{Mn}{ }_{11} \mathrm{Ni}_{14}$, and $\mathrm{Al}_{2} \mathrm{Cu}$. The spatial distribution of these intermetallic phases has been found to vary within a given molten pool. The solidification sequence and the various mechanisms involved in the formation of this peculiar microstructure are discussed in the light of our multi-scale microstructural observations along with solidification thermodynamic calculations.
\end{abstract}

Keywords: Laser powder bed fusion (L-PBF); Al-alloys; Microstructure; Additive Manufacturing; TEM

\section{Introduction}

Aluminium alloys are used in aerospace and automotive applications for their excellent strengthto-weight ratio. The development of additive manufacturing, especially the laser-power bed fusion process (L-PBF), opens the way through more advanced geometrical design to reach additional weight saving [1]. Aluminium casting alloys such as AlSi10Mg or AlSi12 are relatively easy to process by LPBF [2],[3]. However, the strength of these casting alloys produced by L-PBF [4] is often insufficient to bring competitive weight-saving solutions given the high cost of the L-PBF process. Producing high strength alloys from the 6XXX [5] and 7XXX series [6] by L-PBF has met with major difficulties due to hot cracking sensitivity along columnar high angles grains boundaries [7].

Different strategies have been developed to mitigate cracking, including optimizing processing parameters, modifying alloy composition or adding nanoparticles such as $\mathrm{ZrH}_{2}$ [8] or Yttrium Stabilized Zirconia (YSZ) [9] to refine the grain size. A successful attempt has been reported for the 6061-grade in [5] by preheating the substrate to high temperatures. However, this requires substantial machine modifications. Another strategy consists in changing the chemical composition of existing alloys. Addition of significant amounts of silicon allows cracks to be suppressed in 7075 but impacts age- 
hardening response in this system [10]-[11]. It has also been demonstrated that the addition of transition metals such as Zirconium or Scandium is an efficient way to produce crack-free samples of high-strength Al-alloys while maintaining good mechanical properties at room temperature [12]. The primary $\mathrm{Al}_{3} \mathrm{X}$ $(\mathrm{X}=\mathrm{Zr}$ or $\mathrm{Sc}$ ) phase promotes heterogeneous nucleation resulting in finer grains, which leads to a decrease of the hot cracking sensitivity. This strategy has been applied to conventional alloys ( $\mathrm{Zr}$ modified 2XXX series [13]) as well as the rapid solidification alloy Scalmalloy® and similar compositions, see e.g. Al-Mg-Sc-Zr [14] or Al-Mg-Zr [12]-[15].

In addition to avoiding hot cracking, alloy design for L-PBF should consider the specific processing conditions and in particular the very high cooling rates to take full advantage of the possibilities offered by the process. Given the high cooling rates, out-of-equilibrium microstructures are likely to develop with a high degree of metastability. This allows new alloy design strategies, with alloying additions beyond the solubility limits imposed by conventional processing through a solution heat treatment. In this context, very recently, some research groups have explored new compositional space in order to design Al alloys specifically for L-PBF, see e.g. Al-Mg-Si-Sc-Zr [16] and Al-Mn-Sc [17], [18].

The objective of the present study is to bring insights into the process-structure relationships of a novel $\mathrm{Al}-4 \mathrm{Mn}-3 \mathrm{Ni}-2 \mathrm{Cu}-2 \mathrm{Zr}$ (in \%weight) processed by L-PBF. This novel alloy has been identified as one of the most promising candidates after exploring a wide range of compositional space in the Al-Mn-Ni$\mathrm{Cu}-\mathrm{Zr}$ alloying system because it shows good processability without hot cracks and exhibits, in its asbuilt condition, good mechanical properties at room temperature: a tensile strength of nearly $500 \mathrm{MPa}$ combined with a relatively good ductility (elongation-to-failure of about $8 \%$, see the tensile curve given in Figure S1 as supplementary material), as well as a thermal stability up to $200-250^{\circ} \mathrm{C}$, temperatures at which the mechanical properties of traditional Al-alloys are drastically reduced. The choice of this alloying system has been based on the following rationale: $\mathrm{Zr}$ additions are employed to refine the microstructure and thus mitigate hot cracking and were chosen rather than Sc-additions due to costefficiency considerations. Other alloying elements have been selected to retain the excellent mechanical properties at higher homologous temperatures through the addition of slow-diffusing alloying species such as $\mathrm{Zr}$ and $\mathrm{Mn}$ combined with the addition of fast-diffuser solutes such as $\mathrm{Cu}$ and $\mathrm{Ni}$ that promote the formation of intermetallic phases that are thermally stable up to $250^{\circ} \mathrm{C}$.

In the present work, based on a multiscale investigation of the microstructure, we identify key microstructural features specific to this $\mathrm{Al}-4 \mathrm{Mn}-3 \mathrm{Ni}-2 \mathrm{Cu}-2 \mathrm{Zr}$ alloy processed by $\mathrm{L}-\mathrm{PBF}$. These specific features inherited from the solidification sequence are then discussed in the light of the typical processing conditions of L-PBF coupled with thermodynamic calculations. Investigating the effect of the specific microstructural features evidenced in this study on the mechanical properties at room and elevated temperatures of this new alloy designed for L-PBF is the aim of an ongoing work.

C'est genant d'expliciter le but du travail en cours en fin d'intro, alors qu'on s'attend à voir expliciter le but du present papier. Dans l'abstract c'était tres bien dit : on pourrait presque le reprendre tel quel. Je propose de remplacer « Investigating the effect .... is the aim of an ongoing work" by

The aim of the present study is to establish the relationships between the processing conditions and the specific features of the microstructure inherited from L-PBF, using a multi-scale microstructural characterization approach and thermodynamical calculation. Eventuellement on peut rajouter: The link with the mechanical properties is the subject of an ongoing work.

\section{Experimental procedures}

\subsection{Materials \& processing conditions}

The material under investigation is a new $\mathrm{Al}-4 \mathrm{Mn}-3 \mathrm{Ni}-2 \mathrm{Cu}-2 \mathrm{Zr}$ alloy processed by L-PBF. The chemical composition of the powder was measured by inductively coupled plasma atomic emission spectroscopy (ICP-AES) analysis and is given in \%.wt in Table 1. Pre-alloyed powder with particle sizes ranging from 10 to $70 \mu \mathrm{m}$ was loaded into a L-PBF machine (EOS M290) equipped with a 
Gaussian $400 \mathrm{~W}$ fiber laser with a spot size of $80 \mu \mathrm{m}$ in a high purity argon environment $(0,2 \% \mathrm{O} 2)$. The specimens were built with a laser power of $370 \mathrm{~W}$, a laser scan speed of $1613 \mathrm{~mm} / \mathrm{s}$, a hatching distance of $143 \mu \mathrm{m}(\mathrm{h})$, and a layer thickness of $60 \mu \mathrm{m}$ (e). A scan strategy using 4mm-stripes and bidirectional scanning has been chosen with a $67^{\circ}$ rotation between consecutive layers. The build platform temperature was set at $200^{\circ} \mathrm{C}$. After processing, samples were submitted to a stress relief heat treatment at $300^{\circ} \mathrm{C}$ for 4 hours before being removed from the build platform.

\begin{tabular}{ccccc}
\hline $\mathrm{Al}$ & $\mathrm{Mn}$ & $\mathrm{Ni}$ & $\mathrm{Cu}$ & $\mathrm{Zr}$ \\
\hline $\mathrm{Bal}$. & 3.87 & 3.14 & 1.86 & 1.89 \\
\hline
\end{tabular}

Table 1: Chemical composition given in \%.wt of the pre-alloyed powder batch of this new Al-alloy designed for L-PBF and used in the present study.

\subsection{Microstructural analysis and phase identification}

Microstructural investigations have been carried out combining several techniques depending on the scale of interest. Investigations at submillimeter and micron scales were respectively performed with an opto-numerical Olympus DSX500 microscope and a Zeiss Gemini SEM 500 FEG equipped with an EBSD detector. Samples have been cold mounted in an epoxy resin and mechanically ground using SiC abrasive papers down to the $\mathrm{P} 4000$ grade followed by a polishing step with a $1 \mu \mathrm{m}$-diamond suspension. Finally, a vibratory polishing using a $0.06 \mu \mathrm{m}$ colloidal silica solution has been carried out with the VibroMet Buehler device. Throughout the manuscript, the build direction is laying in the field of view. Electron Back Scattered Diffraction (EBSD) was performed to study the crystallographic orientation of the FCC-Al matrix at different scales. Several step sizes, from $200 \mathrm{~nm}$ to $50 \mathrm{~nm}$, have been employed depending on the scale studied. Such information will be systematically given in the corresponding figure caption. Note that for all EBSD orientation maps, the confidence index that measures the quality of the diffraction patterns, is superimposed onto the IPF-color code orientation map. Points having a confidence index smaller than 0.1 will be displayed in black in EBSD orientation maps.

For characterizing the microstructure at the micron scale, TEM has been carried out on thin foils prepared by electropolishing with a Tenupol 5 using a solution consisting of $30 \%$ Nitric acid $70 \%$ methanol at $-35^{\circ} \mathrm{C}$ and $20 \mathrm{~V}$. To further characterize specific regions of interest, lamellae were extracted from those regions using a Focused Ion Beam (Zeiss NVision 40 Ga FIB-SEM). An initial $1 \mu$ m-thick lamella protected by carbon and platinum (total thickness $1 \mu \mathrm{m}$ ) is extracted from the bulk. Successive Ga milling allows the thickness of the lamella to be reduced to less than $100 \mathrm{~nm}$ over a length of about $6 \mu \mathrm{m}$. The last thinning steps are performed on both sides of the lamella at an accelerating voltage of $30 \mathrm{kV}$ with a probe current of $40 \mathrm{pA}$ and a $0.8^{\circ}$ grazing angles. TEM conventional Bright Field (BF) and Dark Field (DF) images were acquired on a JEOL 3010 Transmission Electron Microscope (TEM) operating at $300 \mathrm{kV}$. The Energy-dispersive X-ray spectroscopy (EDS) has been carried out on a TEM FEG JEOL 2100 operating at $200 \mathrm{kV}$ using a high collection angle SDD Centurio detector. In the present work, the EDS results are considered only for relative comparisons.

To characterize the phases, present in the microstructures, X-Ray Diffraction (XRD) was performed on samples produced by L-PBF with a PANalytical X'PERT MPD instrument equipped with a 1D detector and a copper source $(\lambda=1.5041 \AA)$. Diffraction patterns were recorded on an angular range starting from the lowest possible angles (in practice $12^{\circ}-80^{\circ}$ ) for a better detection of the phases with large lattice parameters. The indexing of the diffraction patterns was done using the ICDD PDF4+ database.

In the different regions identified at the melt pool scale, ACOM (Automated Crystallographic Orientation Mapping) was performed with the hardware and software toolset ASTAR ${ }^{\mathrm{TM}}$ from Nanomegas to retrieve the local phase and orientation information. The details of this technique are given in ref. [20]. To summarize, a nano-beam is scanned over the area of interest and, in each point of the scan, diffraction patterns are acquired with a CCD camera. By post-processing the diffraction data set, the phase and orientation at each position is assigned by comparison to simulated patterns of candidate phases using a template matching technique. As ACOM only establishes correlations between 
acquired and simulated patterns, a careful preliminary work is required to establish candidate phases. The list of candidate phases was established based on XRD analysis and preliminary thermodynamic calculations. The quality of the matching between experimental and calculated patterns is evaluated by two indices: the correlation index I and the phase or orientation reliability R. The correlation index (I) measures the correlation between the experimentally recorded pattern and the theoretical template of a given phase. The simulated pattern having the highest correlation index with the acquired diffraction pattern determines the best solution. The phase/orientation reliability index $\mathrm{R}$, overlaid on the patterns is defined as $R=100\left(1-I_{1} / I_{2}\right)$ with $I_{1}$ and $I_{2}$ the correlation indices of the two best solutions for respectively the candidate phase or orientation. When this parameter $\mathrm{R}$ is above 15 , it is considered sufficient to ascertain that the identified phase is by far the best solution out of all candidates [20].

\section{Experimental Results}

\subsection{L-PBF processability}

Figure 1a shows an optical micrograph of a sample built by L-PBF and observed in a plane containing the build direction. It is worth noticing that the sample was found to be crack-free, only a few spherical pores were detected, see red arrows in Figure 1a. The overall porosity content was estimated to be less than $0.5 \%$ using image analysis. The few pores and more importantly the absence of cracks demonstrate the good processability of this alloy by L-PBF compared to what is often reported for conventional agehardenable aluminium alloys fabricated by L-PBF, see e.g. [5], [6], [21]. Figure 1b shows an optical micrograph taken after chemical etching that reveals the arrangement of the different melt pools. The contrast induced by chemical etching allows the effect of convective flows on the microstructure to be evidenced, see yellow arrows in Figure 1b. The characteristics of the different zones appearing with various grey levels in Figure 1b will be discussed later.
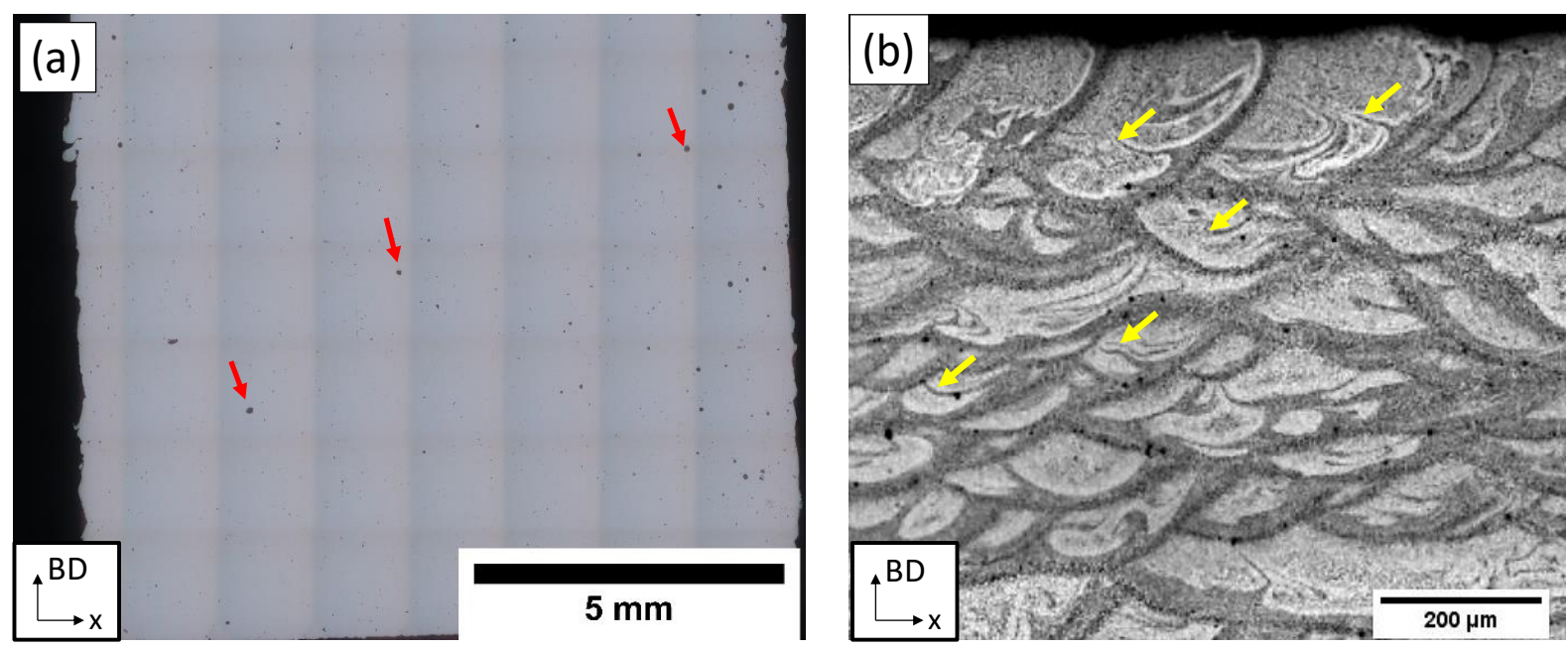

Figure 1: Macroscopic view of a sample built by L-PBF. (a) Optical micrograph taken along the build direction showing a low content of porosity (see red arrows pointing out pores) and no crack parallel to the building direction. (b) Optical micrograph after a $7 \mathrm{~s}$-Keller chemical etching revealing the melt pools morphology and the signature of convection during solidification (yellow arrows). 


\subsection{Overview of the macro- and microstructure}
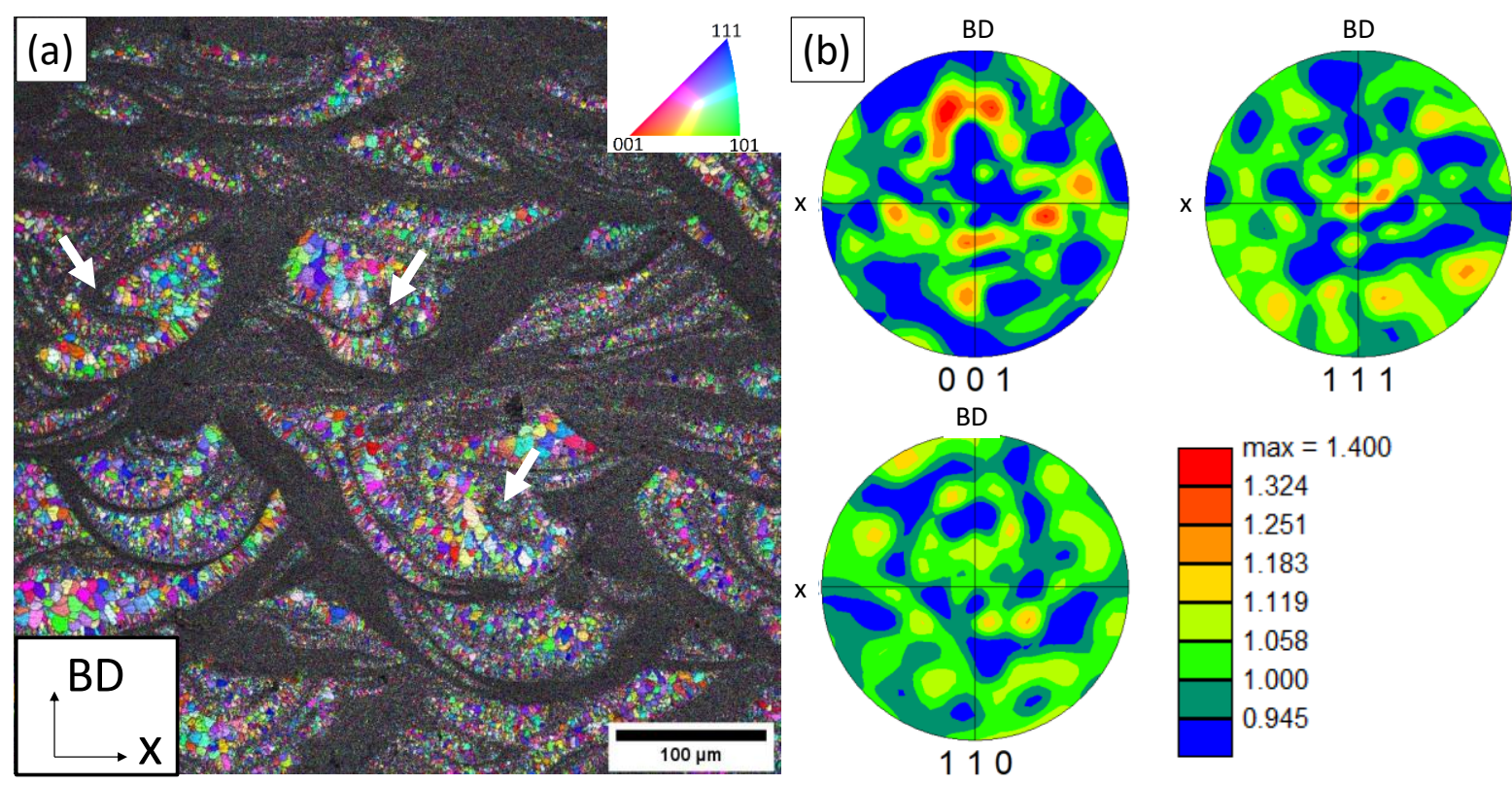

111

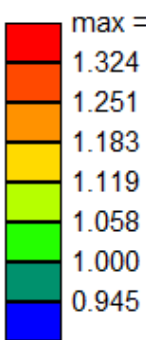

Figure 2: (a) IPF-EBSD orientation map of aluminium normal to the $Y$-axis and superimposed with the confidence index map showing the macrostructure along the build direction. Step size $=200 \mathrm{~nm}$. The low confidence index regions (index below 0.1) are displayed in black. (b) (001), (110) and (111) pole figures showing that the as-built microstructure exhibits a relatively random texture.

To get an overview of the grain structure and texture, EBSD measurements were performed on a large field of view including several melt pools. EBSD data were collected considering only the aluminium FCC-phase. Figure 2a shows the inverse pole figure (IPF) orientation map in a section containing the build direction (BD). In this map, the hemispherical shape of the melt pool indicates that the processing conditions lead to a conduction regime rather than a keyhole regime [28]. The stacking of adjacent melt pools resulting from the laser scanning strategy combined with convection produce a relatively complex grain architecture. Figure 2a shows the presence of regions with high (coloured) and low (in black) confidence index which highlights the heterogeneous and hierarchical nature of the grain structure. One should also note the presence of narrow bands with a low confidence index within melt pools, see white arrows in Figure 2a. Also, Figure 2a does not show elongated columnar grains growing through several melt pools along the build direction as usually reported for more conventional aluminium alloys produced by L-PBF [29],[30]. The epitaxial growth of columnar grains from the previous layer as typically reported in [3] appears to be limited by the formation of a new melt pool. The grain structure of the studied alloy is rather similar to that of other aluminium alloys containing zirconium and/or scandium, see e.g.[14], [15], [31], [32].

Figure 2b exhibits the (001), (110) and (111) pole figures extracted from the high confidence index zones in Figure 2a. The maximum intensity of the texture is 1.4, demonstrating that the texture can be considered as relatively random. This is unlike conventional aluminium alloys derived from castings and produced by L-PBF ( $\mathrm{AlSi}_{10} \mathrm{Mg}$ [33], Al-12Si [34]) showing a strong <100> texture with elongated columnar grains (typically 100-200 $\mu \mathrm{m}$ in length) [3]. In the present case, no grain exhibits a size larger than the melt pool. Additional investigations are needed to characterize the microstructure at a finer scale, especially in low confidence index regions (Figure 2a). 
Figure 3a shows an IPF orientation map at the scale of the melt pool which evidences the changes in aluminium grain morphology from center to the top of the melt pool resulting in a hierarchical architecture to the grain structure. Figure 3b is an enlarged view of the top of the melt pool (yellow framed region in Figure 3a) showing equiaxed grains with a size larger than $5 \mu \mathrm{m}$. Figure 3c is an enlarged view of the center of the melt pool (light blue-framed region in Figure 3a). More elongated grains with a growth direction aligned with the main thermal gradient direction can be observed. Their lengths are smaller than $20 \mu \mathrm{m}$ (melt pool depth $\approx 150-200 \mu \mathrm{m}$ ). Based on these observations, the high confidence index zone can be divided in two different sub-regions: a coarse equiaxed grains zone (CEZ) and a columnar grain zone (CZ). Figure 3d shows the IPF orientation map of a low confidence index zone (framed in red in Figure 3a) determined using ACOM. Based on Figure 3d, the grain structure in this region consists of sub-micrometer sized equiaxed aluminium grains. Figure 3f shows the (001), (110) and (111) pole figures calculated from the orientation map displayed in Figure 3d. The maximum intensity of the texture is less than 2. Thus, this region can be considered as randomly oriented as well. These observations lead us to define this region as the fine equiaxed zone (FEZ).

Owing to their chemical contrast, the BSE-SEM images in Figure 3(f-h) provide complementary information regarding the microstructures of the three different regions identified above (fine equiaxed zone (FEZ); columnar zone (CZ); and coarse equiaxed zone (CEZ)). In these images, the aluminium matrix appears dark while the second phase particles appear bright. From Figure 3(f-h), image analysis allows estimations of the fraction of second phase particles in each zone : $f_{\text {precipitate,FEZ }}=27 \pm$ $2 \%, f_{\text {precipitate }, C Z}=21 \pm 2 \%$ and $f_{\text {precipitate }, C E Z}=21 \pm 2 \%$. Such a high fraction of second-phase particles in the as-built conditions can be considered as a specific feature of this novel alloy processed by L-PBF in comparison to most of the Al-alloys developed for L-PBF, see e.g. [12]-[15], [16]. From Figure 3g-h a substantial part of these second phase precipitates seems to be distributed in the intergranular or interdendritic regions. The volume fraction of precipitates differs between the different zones, it seems higher in the FEZ than in the two other regions (CZ and CEZ). However, the main difference revealed by Figure 3f-h is the morphology and the spatial distribution of the second phase particles: they appear rather isolated with a globular morphology in the FEZ whereas they show a more continuous and vermicular morphology in both the CZ and the CEZ. 

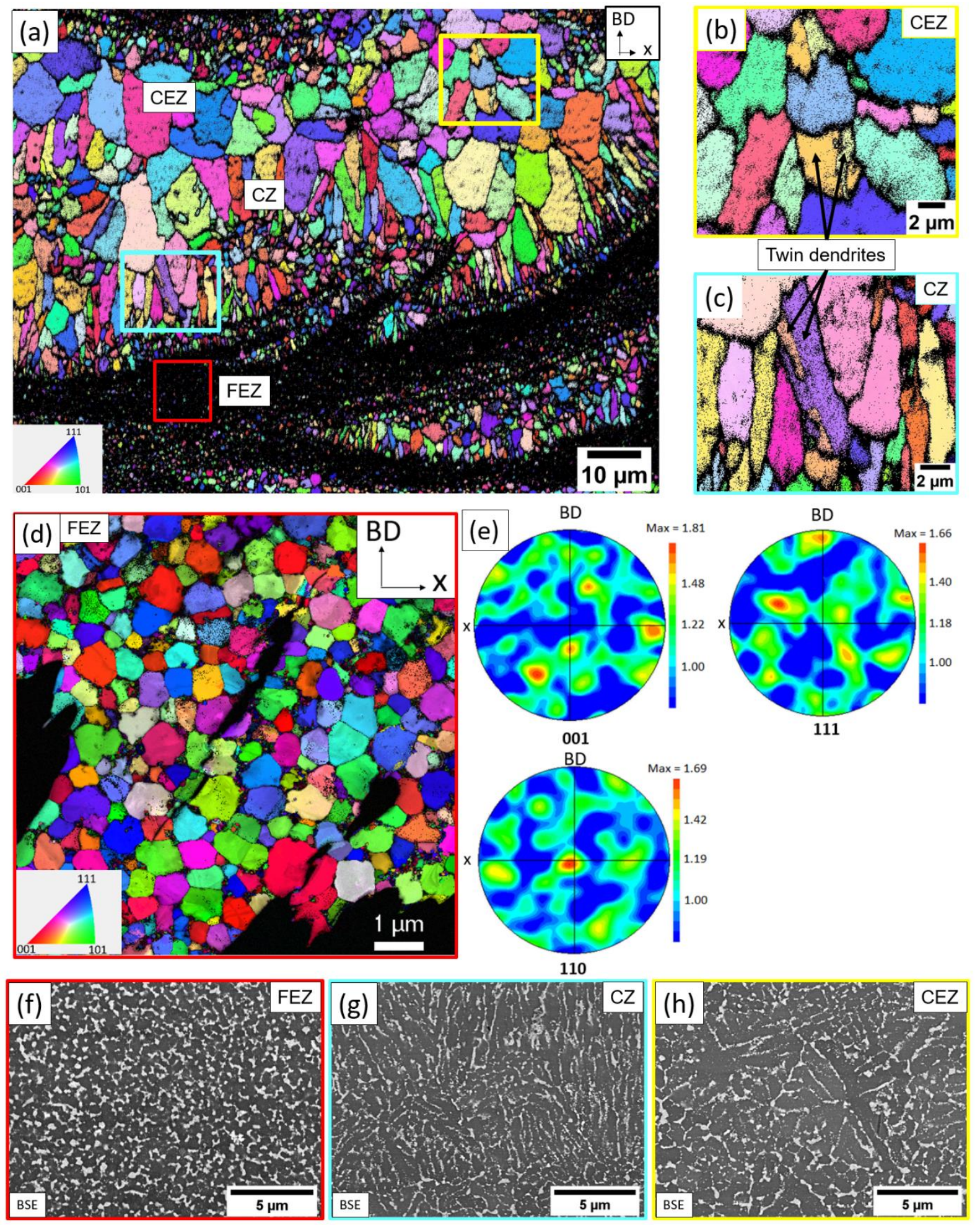

Figure 3: Overview of the macro- and microstructure at the scale of the melt pool. (a) IPF-EBSD orientation map normal to the $Y$-direction acquired with a step size of 100nm. The low confidence index zone is associated to the presence of very fine equiaxed grains (<1um), and the high index one consists of columnar grains as well as coarse equiaxed grains. (b)-(c) Enlarged view showing dendrites in the coarse equiaxed and columnar zones identified as twins by the crystallographic analysis. (d) IPF orientation map normal to the $Y$-direction acquired using ACOM in a zone typical of the fine equiaxed zone (FEZ) (step size = $15 \mathrm{~nm})$. Only aluminium was indexed and the orientation map is overlapped with the greyscale reliability map. (e) (001), (110) and (111) pole figures extracted from the region of interest shown in $(d)$. BSE-SEM micrographs illustrating the three different microstructures observed on the as-built samples in the : (f) fine equiaxed zone (FEZ); $(g)$ columnar zone (CZ); and ( $h$ ) coarse equiaxed zone (CEZ). 
Figure 4a shows a TEM- bright field (BF) micrograph illustrating the transition from the FEZ to the CZ. In the upper region of Figure 4a, the aluminium grains exhibit a columnar dendritic morphology corresponding to the $\mathrm{CZ}$, whereas in the FEZ below they show a more equiaxed shape. The size of the columnar grains is much finer than what is usually reported for Al-alloys produced by L-PBF, see e.g. [2],[3]. One should note the peculiar morphology of some of the columnar dendrites which exhibit a palm-tree appearance, see typically the Figure 4c. This palm-tree appearance unreported yet in the literature dealing with $\mathrm{Al}$-alloys processed by L-PBF, shows that the growth directions for the dendrite primary trunks as well as the secondary dendrite arms are unlikely to be the expected $<001\rangle$-directions [35]-[37]. In addition, the presence of some twinned dendrites in the CZ and CEZ, as exemplified in Figure 4b-c should also be emphasized as it can be seen as a specific feature of this new alloy processed by L-PBF. The twin relationship has been verified by stereographic analysis, see Figure S2. Figure 4b is an enlarged view of the FEZ where square-shaped precipitates about $200 \mathrm{~nm}$ in size are almost systematically observed at the centre of the submicronic equiaxed aluminium grains (red arrows). Note that the equiaxed dendrite in Figure 4b shows very limited arms. Figure 4(a-b) also suggest that intergranular or interdendritic regions are decorated by precipitates smaller than $500 \mathrm{~nm}$ regardless the observed zone. This is consistent with the position of the second phase particles shown in Figure 3(fh).
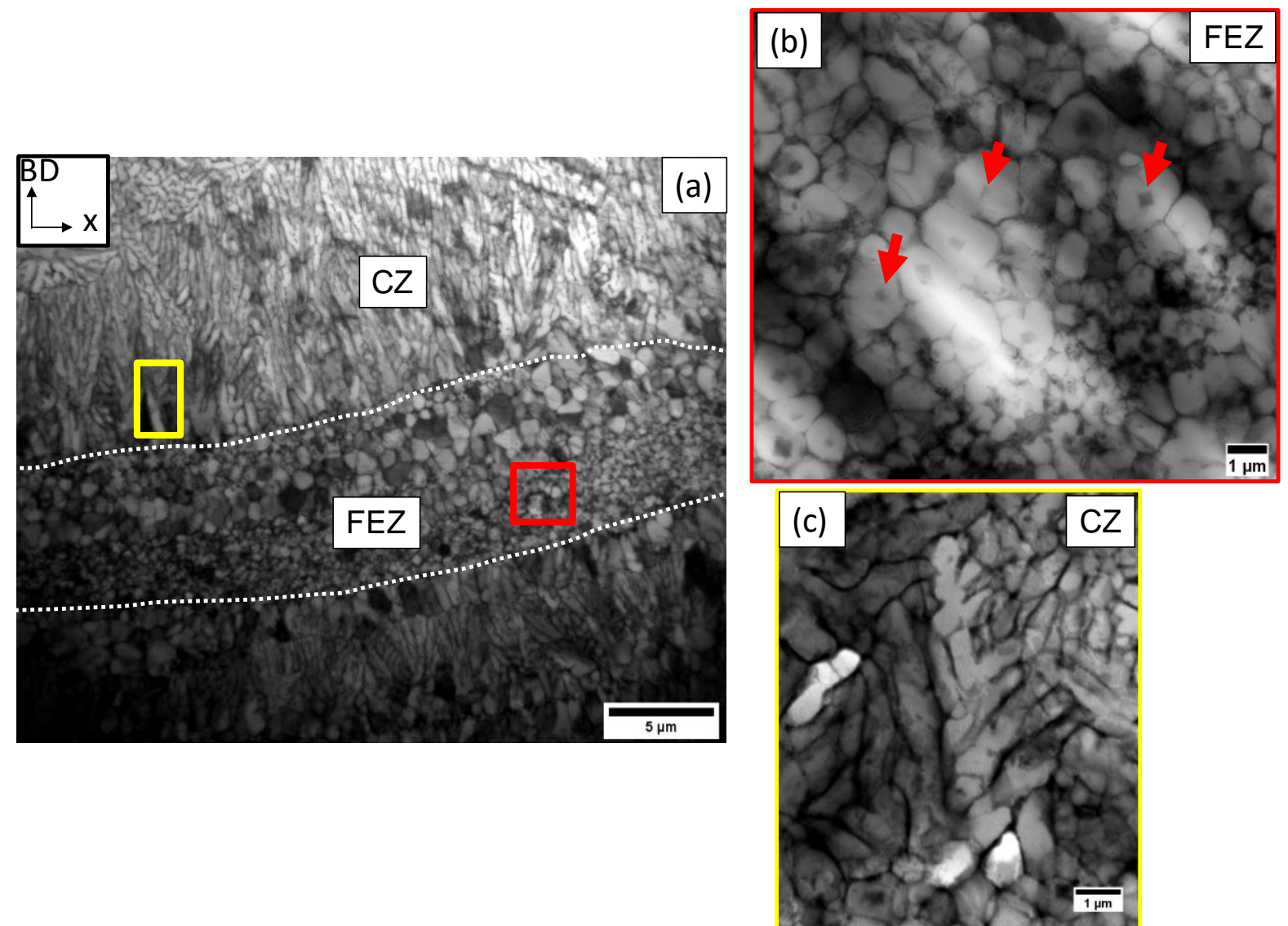

Figure 4: TEM micrographs using the Bright Field (BF) contrast illustrating: (a) a transition from the fine equiaxed zone (FEZ) to the columnar one (CZ) along the build direction. The white dotted line represents the boundary between the two zones. (b) An enlarged view of the red square in (a) showing some square-shape precipitates pointed out by red arrows at the grain center in the FEZ. (c) An enlarged view of a typical zone in yellow square in (a) showing a columnar dendrite with a palm tree appearance. 


\subsection{Phase identification}

Figure 3 (f-h) has proven the presence of a substantial fraction of other phases. These phases are located at in the intergranular or interdendritic regions (second phases) between them (FEZ, CZ and CEZ, see Figure 3f-h) as well as at the centre of the Al grains (primary phases observed in the FEZ, see Figure 4b). Thus, XRD analyses have been carried out in order to identify the nature of the different phases.

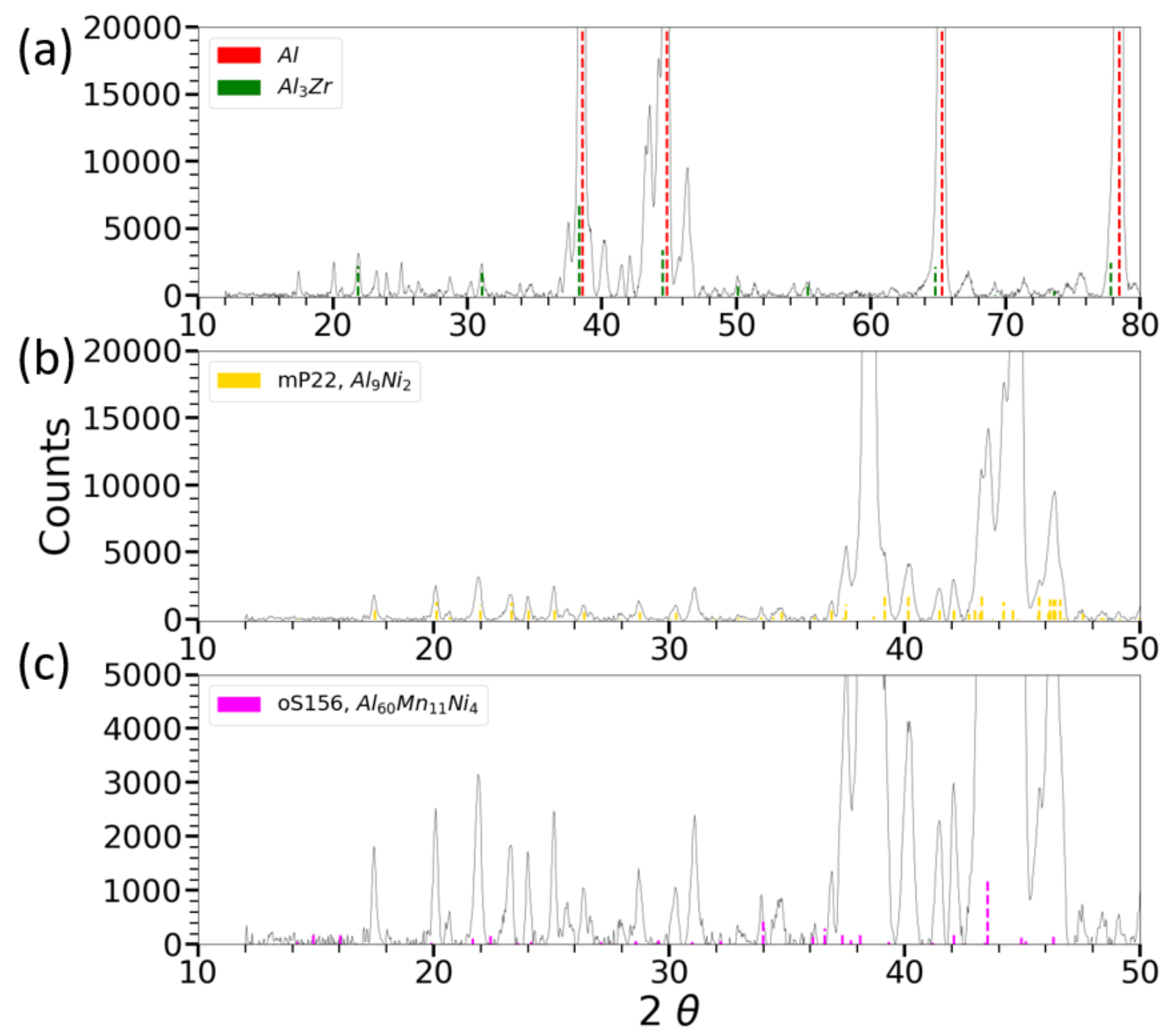

Figure 5: XRD patterns obtained from an as-built sample. (a) In the $\left(10^{\circ}, 80^{\circ}\right)$ angular range, the main diffraction peaks are indexed as FCC-Aluminium ( $a=4.04317 \AA$, red dashed lines) and $A l_{3} Z r-L 1_{2}$ structure $(a=4.069 \AA$, green dashed lines). $(b)$ and (c) Enlarged views of the XRD patterns in the $10-50^{\circ}$ range. (b) The yellow dotted lines can be indexed as a monoclinic structure with lattice parameters $a=6.23752 \AA, b=6.28521 \AA, c=8.62636 \AA, \beta=95.705$ consistent with the Al9Ni2 phase (structure type $\mathrm{Al} 9 \mathrm{Co} 2$, Pearson symbol $\mathrm{mP22}$ ). (c) The pink dotted lines can be indexed as an orthorhombic structure with lattice parameters $a=7.55 \AA, b=23.8 \AA c=12.5 \AA$ associated to the structure type Al6oMn ${ }_{11} \mathrm{Ni}_{4}$ phase (Pearson symbol oS156). The XRD indexing is based on the crystallographic information from the ICCD PDF4+database. Though the exact composition might be different, the various phases will be referred to by the chemical formula from this XRD database.

Based on the indexing of the diffraction patterns shown in Figure 5a, the phases present in significant volume fraction are FCC-Aluminium and a $\mathrm{L}_{12}$ type structure with a lattice parameter equal to $4.069 \AA$, consistent with the $\mathrm{Al}_{3} \mathrm{Zr}$ phase. Smaller signals can also be detected in the diffraction patterns, especially in the $10-50^{\circ}$ range as highlighted in Figure $\mathbf{5 b}$ and Figure 5c. The XRD patterns displayed in Figure 5b and Figure 5c can be respectively indexed with a good agreement as the monoclinic $\mathrm{Al}_{9} \mathrm{Co}_{2}$-structure type and the orthorhombic $\mathrm{Al}_{60} \mathrm{Mn}_{11} \mathrm{Ni}_{4}$-structure type. These structures are consistent with the presence of the $\mathrm{Al}_{9} \mathrm{Ni}_{2}$ and $\mathrm{Al}_{60} \mathrm{Mn}_{11} \mathrm{Ni}_{4}$ phases earlier identified in others Al-alloys [38]-[39] 
but never reported in $\mathrm{Al}$-alloys produced by additive manufacturing. Interestingly, the $\mathrm{Al}_{60} \mathrm{Mn}_{11} \mathrm{Ni}_{4}$ phase exhibits a large lattice parameter with local icosahedral packing. However, this identification using low intensity peaks resulting from the large number of peaks characteristic of structures having large lattice parameters, and from their small volume fractions, may be subjected to caution. Therefore, we conducted a complementary analysis at the nanoscale using the TEM-ACOM method described in section 2.3.

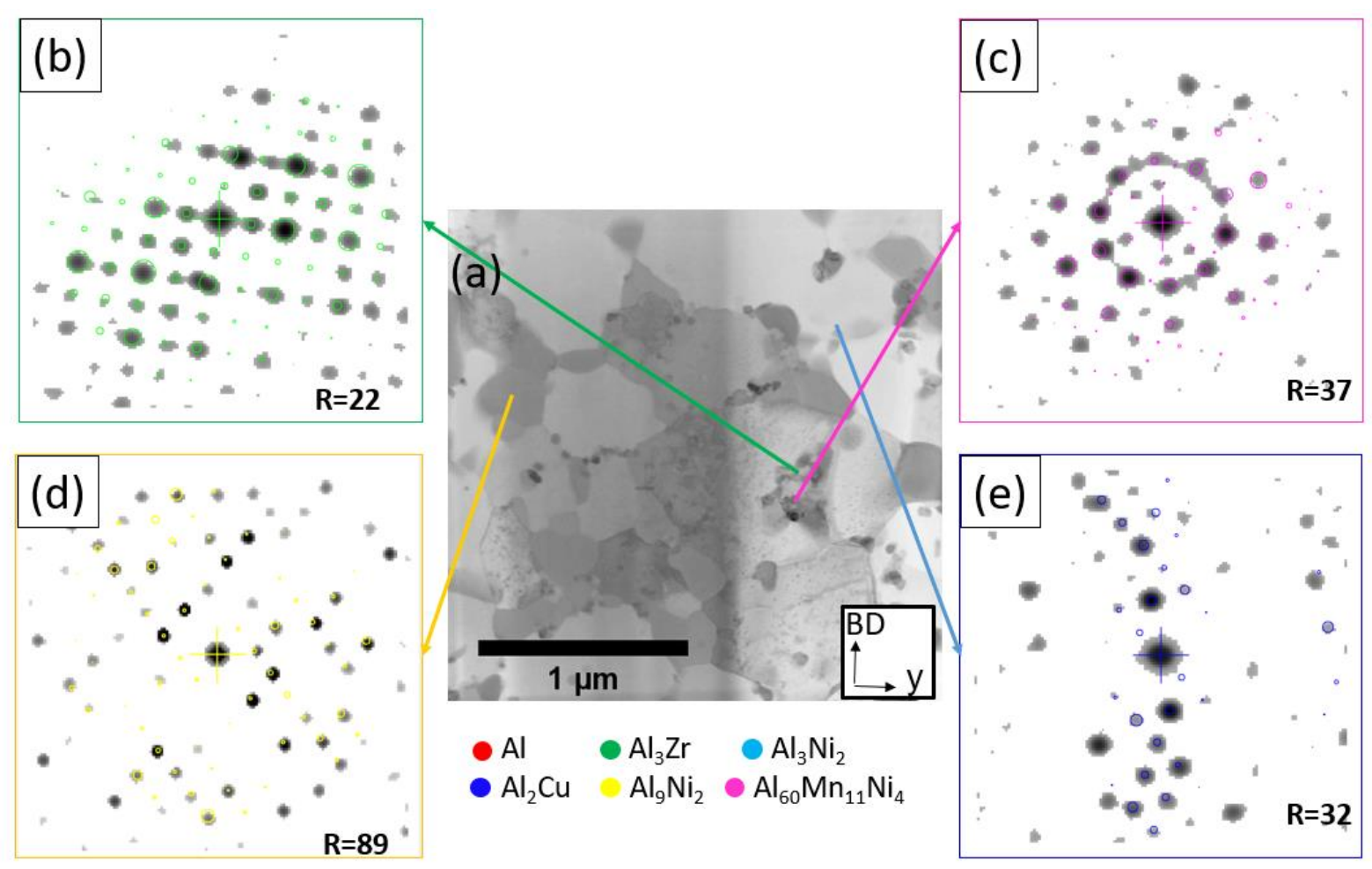

Figure 6: (a) Virtual Bright field of a region of interest taken in the FEZ. (b-c-d-e) Nanodiffraction patterns obtained experimentally (in grey) superimposed with the calculated diffraction patterns (circles) of the structures retrieved from the XRD pattern indexing (Figure 5): (b) $\mathrm{Al}_{3} \mathrm{Zr}-\mathrm{L12}$, (c) $\mathrm{Al}_{60} \mathrm{Mn}_{11} \mathrm{Ni}_{4}$, (d) $\mathrm{Al}_{9} \mathrm{Ni}_{2}$, (e) $\mathrm{Al}_{2} \mathrm{Cu}$. The phase reliability, $\mathrm{R}$, is given for each phase. The diffraction pattern in Figure 7(c) that reminds a 5-fold symmetry can be indexed with the crystalline orthorhombic structure $\mathrm{Al}_{60} \mathrm{Mn}_{11} \mathrm{Ni}$.

The analysis of a series of nanodiffraction patterns recorded over a region of interest extracted from the FEZ is shown in Figure 6a. The experimental patterns have been compared to those simulated with the ASTAR software from the candidate structures identified with the XRD analysis. The overlapping between the experimental patterns and the simulated ones shown in Figure $\mathbf{6 b}$ indicates very good agreement confirming the presence of the $\mathrm{Al}_{3} \mathrm{Zr}-\mathrm{L} 1_{2}$ structure. According to Figure $\mathbf{6 c}$ and Figure $\mathbf{6 d}$, the two other complex phases identified using XRD, namely $\mathrm{Al}_{60} \mathrm{Mn}_{11} \mathrm{Ni}_{4}$ and $\mathrm{Al}_{9} \mathrm{Ni}_{2}$, also give good matching with the experimental diffraction patterns. Two additional minor phases, not detected using $\mathrm{XRD}$, were also identified from the nanodiffraction patterns: the $\mathrm{Al}_{2} \mathrm{Cu}$ phase (tetragonal structure : tI12 $: \mathrm{a}=6.10697 \AA, \mathrm{c}=4.86630 \AA$ that allows to index the pattern in Figure 6e), and the $\mathrm{Al}_{3} \mathrm{Ni}_{2}$ phase (hexagonal structure hP5: $\mathrm{a}=4.0887 \AA$ and $\mathrm{c}=4.90088 \AA$, indexing the pattern given in Figure $\mathbf{S 3}$ provided in supplementary materials). A similar illustration extracted from the $\mathrm{CZ}$ is provided in supplementary material, see Figure $\mathbf{S}$. The spatial distribution of the various identified phases that was found to vary within a given molten pool will be discussed later in sections 0 and 0 .

The diffuse intensity ring in Figure $\mathbf{6 c}$ or in Figure S3 is thought to be caused by the presence of nanocrystallites or amorphization. Since this diffuse ring was not observed for electropolished TEM lamellae, we suspect amorphization to occur during FIB-TEM lamella preparation. The possible impact of FIBoperations is further supported by the EDS map of Ga acquired in the regions of interest that show Gaenrichment at grain boundaries, see supplementary Figure S4. 


\subsection{The Fine Equiaxed Zone (FEZ)}

To study the phase and solute distributions in the FEZ, coupled ACOM and EDS analyses were combined on samples prepared via electro-polishing or FIB and extracted from the FEZ, see Figure 710.
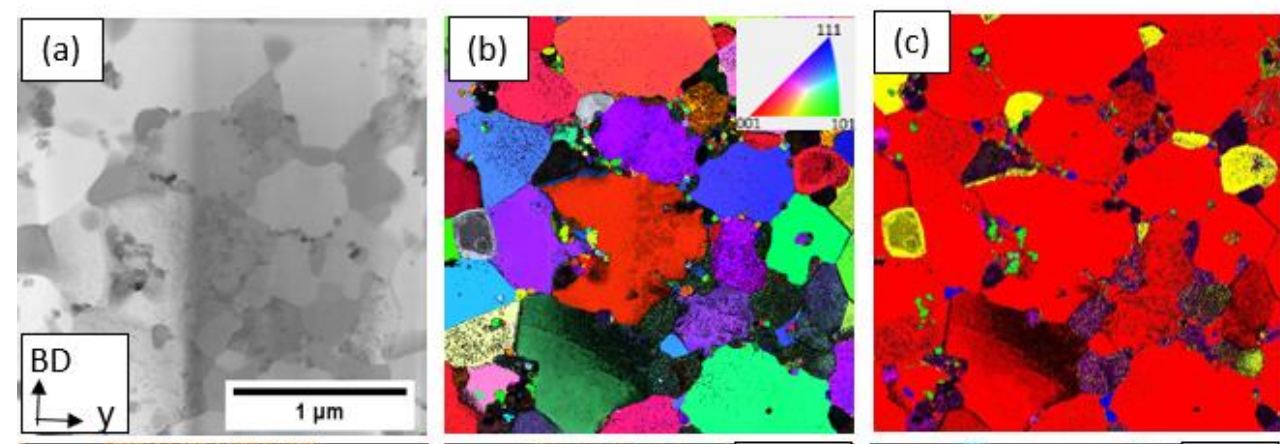

Al
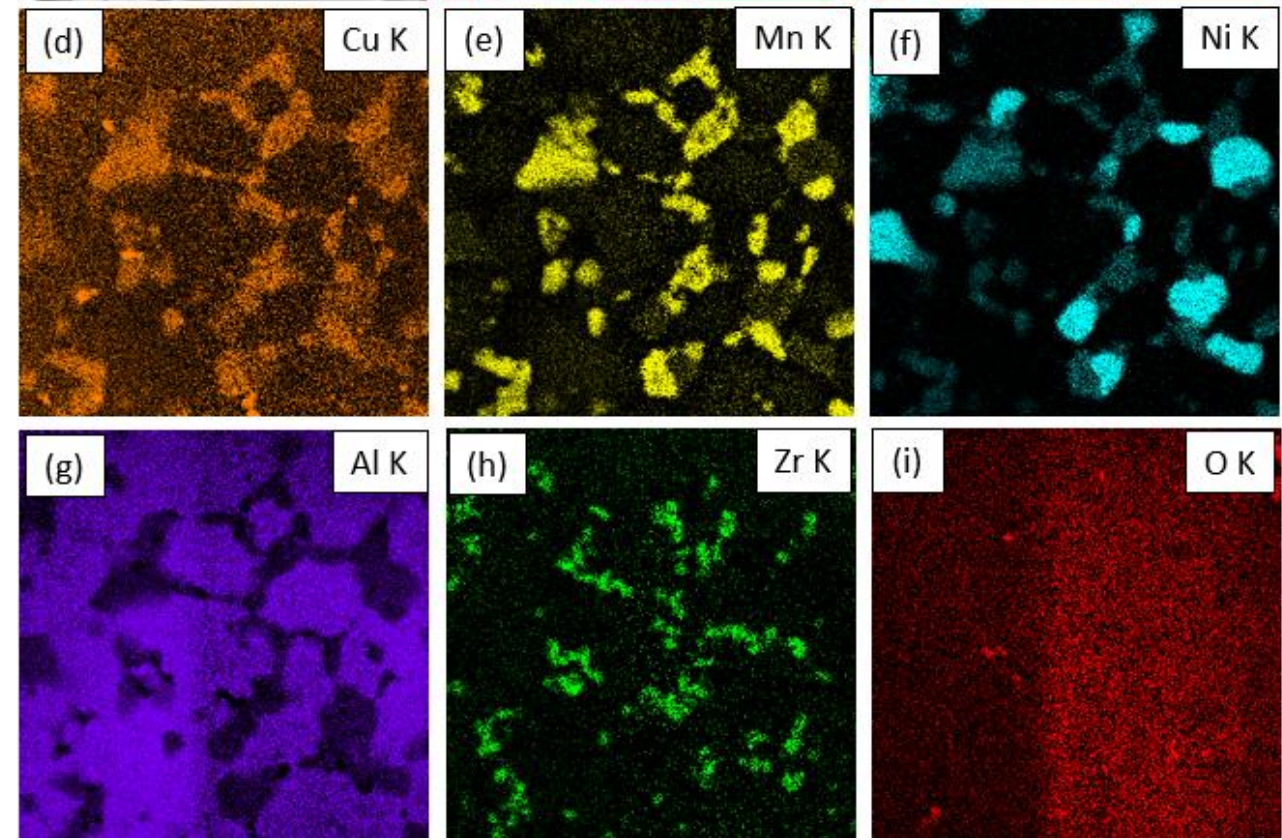

Figure 7: Phase and solute distributions in the FEZ by coupling ACOM and EDS analysis on a TEM lamella made by FIB. (a) Virtual Bright Field image of the region of interest. (b) Crystallographic orientation map normal to the z-direction. (c) Phase map showing the morphology and spatial distribution of the different phases (step size $=5 \mathrm{~nm}$ ). The grey scale corresponds to the phase reliability. EDS maps for the different alloying elements and oxygen: (d) Copper, $(e)$ Manganese, $(f)$ Nickel, $(g)$ Aluminium, (h) Zirconium and (i) Oxygen. Note that orientation maps are always overlapped with the greyscale reliability map.

As expected from a TEM section taken in the FEZ, the microstructure is similar to the one shown in Figure 4b. However, if no square-shape precipitate at the grain center can be observed in Figure 7c we believe that it is just a sampling issue (2D-sectioning of grains) because in other regions of interest taken in the FEZ, we observe those square-shape precipitates at the grain center (see typically Figure 8a-d). Since they contain aluminium and zirconium and are indexed with the $\mathrm{L}_{2}$ structure, they can be identified as $\mathrm{Al}_{3} \mathrm{Zr}$ precipitates. In the interdendritic regions (Figure 7c), numerous particles are observed. The crystal structure of the coarser ones with a size ranging from 200 to $500 \mathrm{~nm}$ is identified as the $\mathrm{Al}_{60} \mathrm{Mn}_{11} \mathrm{Ni}_{4}$ and $\mathrm{Al}_{9} \mathrm{Ni}_{2}$ phases respectively in pink and yellow in Figure 7c. The EDS maps shown in Figure 7d-h are in agreement with the phase map displayed in Figure 7c because the $\mathrm{Al}_{9} \mathrm{Ni}_{2}$ particles contain more Nickel than the $\mathrm{Al}_{60} \mathrm{Mn}_{11} \mathrm{Ni}_{4}$ particles while the latter are richer in Manganese. However, both phases $\left(\mathrm{Al}_{9} \mathrm{Ni}_{2}\right.$ and $\mathrm{Al}_{60} \mathrm{Mn}_{11} \mathrm{Ni}_{4}$ precipitates) contain Aluminium, Manganese, Nickel, and Copper. Interestingly, smaller $\mathrm{Al}_{3} \mathrm{Zr}$ precipitates have been detected in the interdendritic regions as reported in [40] but no simple morphology could be recognized as illustrated in the phase map (particles 
in green in Figure 7c) and Zr-EDS map (Figure 7h). This observation suggests the presence of $\mathrm{Al}_{3} \mathrm{Zr}$ precipitates with different size and morphology depending on their location within the microstructure: at the grain center or in the intergranular regions. In this region of interest, no $\mathrm{Al}_{3} \mathrm{Ni}_{2}$ precipitate has been identified but it was found in other regions of interest, see e.g. Figure $\mathbf{S 5}$. Small $\mathrm{Al}_{2} \mathrm{Cu}$ precipitates $(<50 \mathrm{~nm})$, also decorating the grain boundaries, can be observed in dark blue in Figure 7c. They are also revealed in the Cu-EDS map in Figure 7d. Finally, the O-EDS map in Figure 7i suggests the presence of nanometer-size aluminium-rich oxides but their crystallographic structure could not be identified. Regarding the FCC-Al matrix, the degree of solute content (Mn, Ni, Zr) seems to be relatively low, as suggested by the EDS maps of the different alloying elements in Figure 7d-h, except for $\mathrm{Cu}$. However, due to the extra signal coming from the TEM column and sample holder, the copper content is likely to be overestimated.

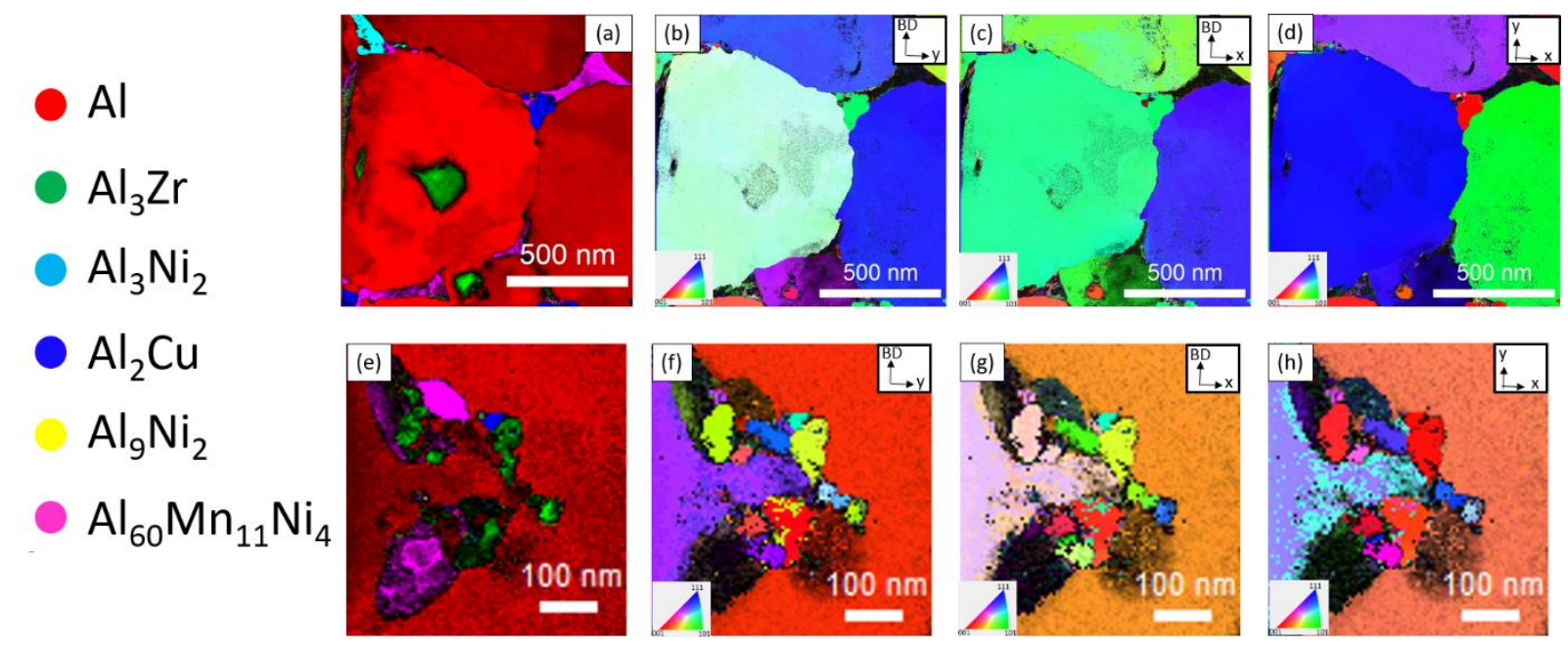

Figure 8: (a) Phase map of a small region of interest in the FEZ (sample prepared by electropolishing) illustrating the first type of $\mathrm{Al}_{3} \mathrm{Zr}$ precipitate located at the grain center (primary phase). The color code associated to the different phases is given at the left of the figure. Crystallographic orientation maps (IPF) for both Aluminium and Al $3 \mathrm{Zr}$ normal to: (b) the $x$-direction, (c) the $y$-direction, and (d) the z-direction (parallel to BD) illustrating the epitaxial growth of the Al-matrix on the L12 metastable Al $\mathrm{Z} \mathrm{Zr}$ phase. (e) Phase map of a region of interest located near a grain boundary illustrating the second type of Als $\mathrm{Zr}$ precipitates located in the interdendritic regions (sample prepared by electropolishing). (f,g,h) Crystallographic orientation maps (IPF) for Aluminium and Al3Zr normal to: $(a)$ the $x$-direction, $(b)$ the $y$-direction, and (c) the $z$-direction (parallel to BD) illustrating the absence of simple orientation relationship between the aluminium matrix and the Al3Zr precipitates.

Figure 8a shows a phase map of a small region extracted from the FEZ, which evidences a $\mathrm{Al}_{3} \mathrm{Zr}$ squareshaped precipitate at the grain center. Figure 8(b-d) displays the orientation maps of the Al-matrix and the $\mathrm{Al}_{3} \mathrm{Zr}$ normal to the $\mathrm{x}, \mathrm{y}$ and $\mathrm{z}$-axis (which correspond to the build direction). These maps reveal that the orientations of the $\mathrm{Al}$-matrix and the $\mathrm{Al}_{3} \mathrm{Zr}$ particle match along the three axes, meaning that the FCC matrix and the $\mathrm{Al}_{3} \mathrm{Zr}$ precipitate have a cube-cube orientation relationship. While this observation is not a new finding, see e.g. [8] or [15], this conclusive evidence is a nice illustration of the benefit of using the ACOM technique to establish orientation relationships in submicrometric grains From Figure 7c and Figure 8e, it can be observed that some smaller $\mathrm{Al}_{3} \mathrm{Zr}$ precipitates, approximately $50 \mathrm{~nm}$ in size, are also located at the grain boundaries. Contrarily to the $\mathrm{Al}_{3} \mathrm{Zr}$ precipitates at the aluminium grain center, Figure 8(f-h) suggests that the $\mathrm{Al}_{3} \mathrm{Zr}$ precipitates located at grain boundaries do not have a simple orientation relationship with the FCC-Al matrix.

Figure 9(a-f) displays the phase (ACOM) and chemical (EDS) maps for another region of interest located in the FEZ. Overall, these results are in agreement with the observations based on Figure 7. However, Figure 9c reveals another interesting feature not reported yet in the literature: the presence of $\mathrm{Al}_{60} \mathrm{Mn}_{11} \mathrm{Ni}_{4}$ precipitates in the core of the grains (see white arrows in Figure 9c). Figure 9b indicates that these precipitates are rich in Manganese and Copper which is consistent with their identification as the $\mathrm{Al}_{60} \mathrm{Mn}_{11} \mathrm{Ni}_{4}$ orthorhombic phase. This observation hitherto unreported suggests that this phase is 
likely contributing to promote grain nucleation in the FEZ. In addition, the $\mathrm{Al}_{60} \mathrm{Mn}_{11} \mathrm{Ni}_{4}$ precipitates located in the core of the grains seem to have a more regular morphology than those observed in the interdendritic regions. The major part of the $\mathrm{Al}_{60} \mathrm{Mn}_{11} \mathrm{Ni}_{4}$ precipitates are, however, located in the interdendritic regions, see Figure 8a and Figure S4.
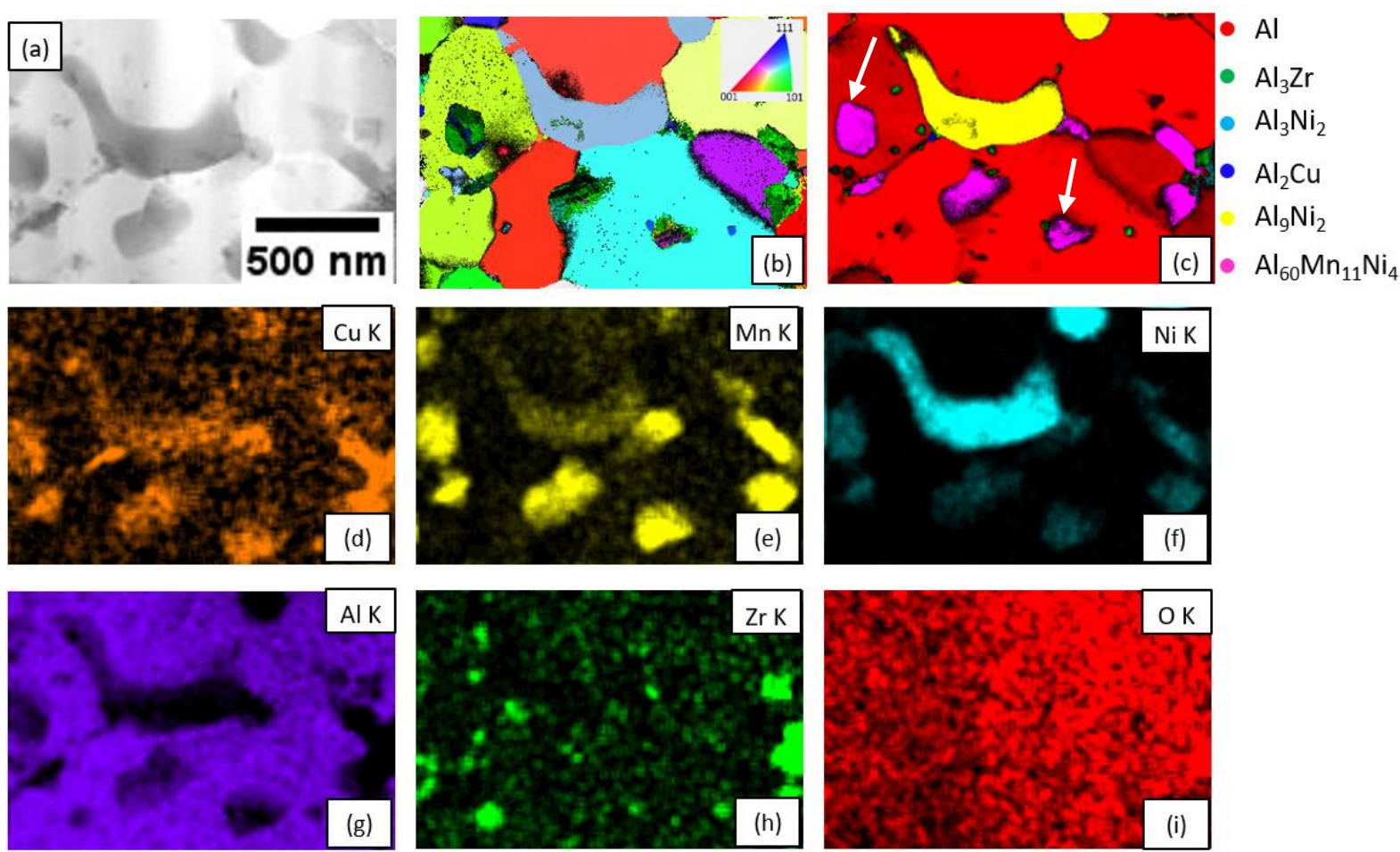

Figure 9: Phase and solute distributions in another region of interest extracted from the EFZ showing some $\mathrm{Al}_{60} \mathrm{Mn}_{11} \mathrm{Ni}_{4}$ precipitates in the core of grains (see precipitates pointed out with white arrows in (c)). (a) Virtual Bright Field image of the region of interest. (b) Crystallographic orientation map normal to the z-direction. (c) Phase map showing the morphology and spatial distribution of phases (step size $=5 \mathrm{~nm})$. EDS maps for the different alloying elements: $(d)$ Copper, $(e)$ Manganese, $(f)$ Nickel, (g) Aluminium, and (h) Zirconium. (i) EDS map for Oxygen. 


\subsection{The Columnar Zone (CZ)}
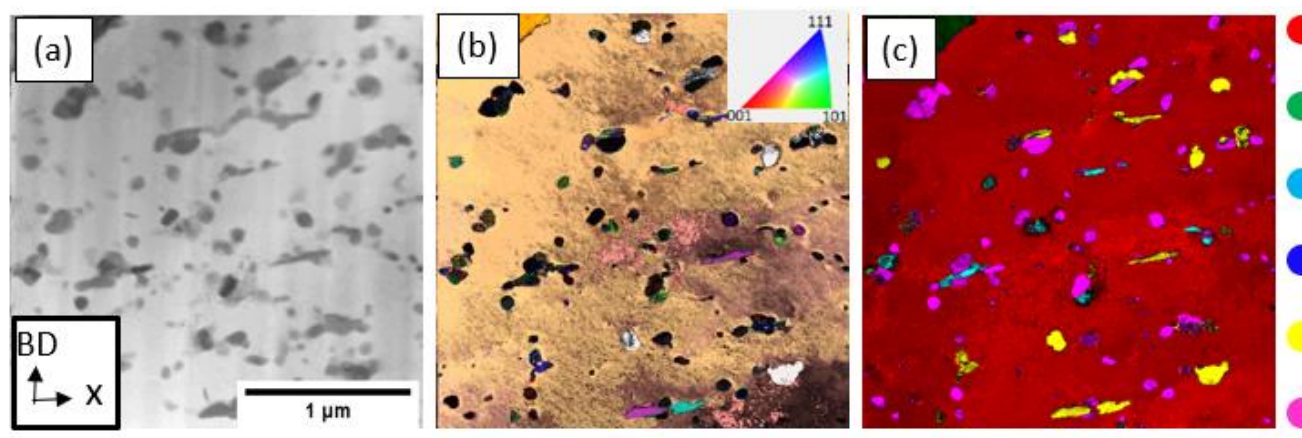

Al

$\mathrm{Al}_{3} \mathrm{Zr}$

$\mathrm{Al}_{3} \mathrm{Ni}_{2}$

$\mathrm{Al}_{2} \mathrm{Cu}$

$\mathrm{Al}_{9} \mathrm{Ni}_{2}$
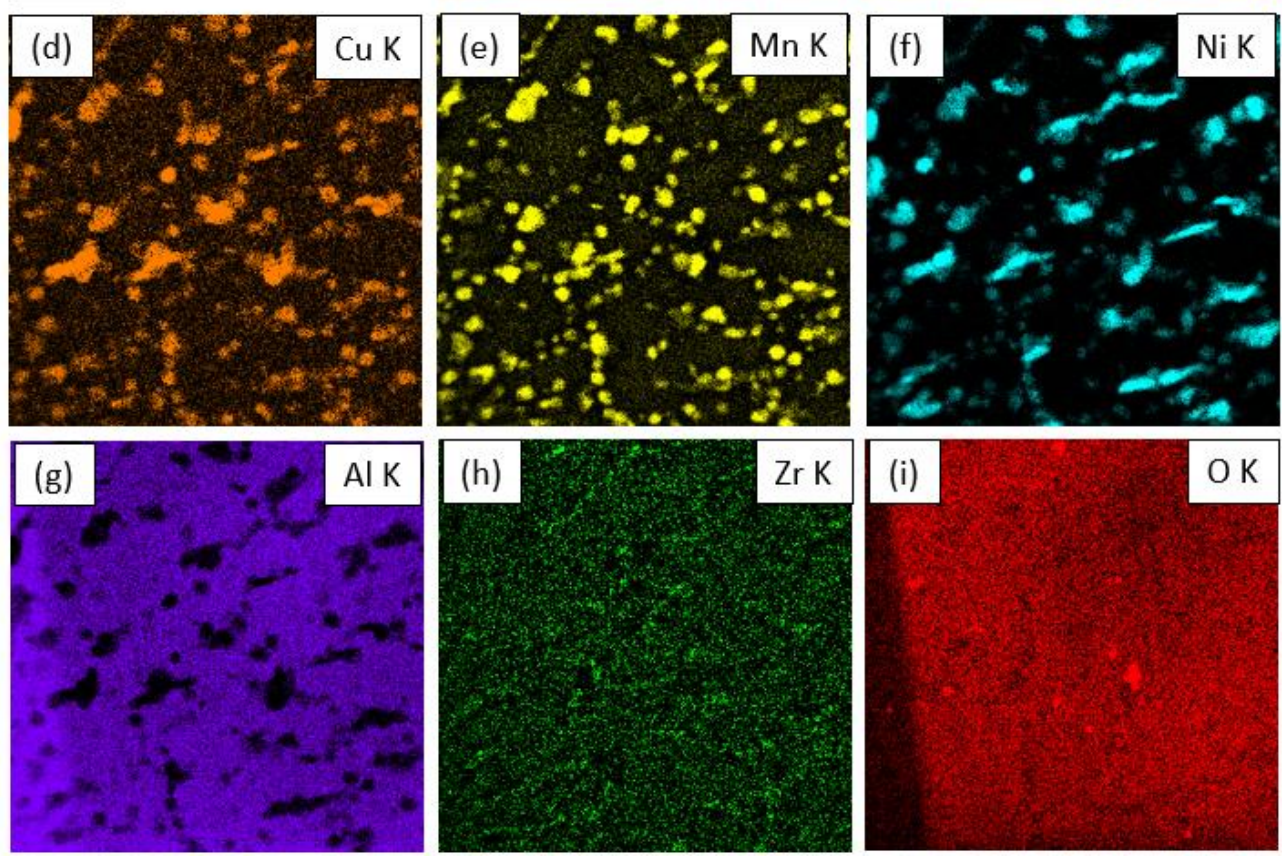

Figure 10: Phase and solute distributions in the CZ by coupling ACOM and EDS analysis on a TEM lamella made by FIB. (a) Virtual Bright Field image of the same region of interest. (b) Crystallographic orientation map normal to the z-direction. The grey scale corresponds to the orientation reliability. (c) Phase map showing the phase spatial distribution and morphology $($ step size $=5 \mathrm{~nm})$. EDS maps for the different alloying elements and oxygen: $(d)$ Copper, $(e)$ Manganese, $(f)$ Nickel, $(g)$ Aluminium, ( $h$ ) Zirconium and (i) Oxygen.

The crystallographic and chemical information have been collected in a region of interest extracted from the CZ, see Figure 10. Because the grain size is larger in this region, only one orientation of the FCCAl matrix can be seen in Figure 10b. In this CZ, precipitates are always located in the interdendritic regions and along the grain boundaries. All the second phase precipitates are smaller $(<200 \mathrm{~nm})$ in this region in comparison with their size in the FEZ, in agreement with the SEM observations shown in Figure 3f-h. Note that here the second phases do not exhibit a continuous morphology as shown in Figure $3 \mathrm{~g}$ because of the 3D nature of the microstructure (here we rather see a cross section of those second phases). Here, no $\mathrm{Al}_{2} \mathrm{Cu}$ precipitates have been detected over this region of interest and only small $\mathrm{Al}_{3} \mathrm{Zr}$ precipitates were detected in the interdendritic spaces. The $\mathrm{Al}_{60} \mathrm{Mn}_{11} \mathrm{Ni}_{4}$ and $\mathrm{Al}_{9} \mathrm{Ni}_{2}$ phases have been identified, respectively shown in pink and yellow in Figure 10c. It should also be highlighted that another phase, namely the $\mathrm{Al}_{3} \mathrm{Ni}_{2}$ phase (hexagonal structure hP5: $\mathrm{a}=4.112 \AA, \mathrm{c}=4.91103 \AA$ and $\gamma=120^{\circ}$, see supplementary Figure S3c) has also been identified in this region. The EDS maps reveals that both the $\mathrm{Al}_{60} \mathrm{Mn}_{11} \mathrm{Ni}_{4}$ and $\mathrm{Al}_{9} \mathrm{Ni}_{2}$ phases are indeed quaternary constituents as they contain Aluminium, Nickel, Manganese and Copper, the former one being richer in Manganese and leaner in Nickel than $\mathrm{Al}_{9} \mathrm{Ni}_{2}$. Interestingly, the $\mathrm{Al}_{3} \mathrm{Ni}_{2}$ phase does not seem to contain $\mathrm{Mn}$. The Oxygen elemental 
map shown in Figure 10i indicates the presence of a few nano sized Al-rich oxide particles. Finally, in comparison with the FEZ, the EDS maps of the various solutes suggest that a substantial amount of Zirconium and to a lesser extent Manganese are retained in the FCC-aluminium dendrite cores, see comparisons between Figure 7d-h (FEZ) and Figure 10d-h (CZ). Regarding the Nickel content in the FCC-aluminium dendrites, it seems relatively similar between the two zones. The difference of solute distribution in the FCC-Al dendrites cores between the FEZ and CZ is further illustrated in Figure S6 where a region of interest taken at the transition between the FEZ and CZ has been characterized. Note that this would need to be further consolidated by characterizing the FCC-aluminium solid solution at the atomic scale to assess that this solid solution is indeed not yet decomposed.

To summarize, at the melt pool scale, three zones have been identified: the fine equiaxed zone (FEZ), the columnar zone (CZ) and the coarse equiaxed zone (CEZ). Coupling chemical analysis with crystallographic analysis, the crystal structure of two different kinds of $\mathrm{Al}-\mathrm{Cu}-\mathrm{Ni}-\mathrm{Mn}$ has been identified as the $\mathrm{Al}_{9} \mathrm{Ni}_{2}$ and $\mathrm{Al}_{60} \mathrm{Mn}_{11} \mathrm{Ni}_{4}$ phases respectively. Additionally, $\mathrm{Al}-\mathrm{Ni}-\mathrm{Cu}$ particles have been identified as the $\mathrm{Al}_{3} \mathrm{Ni}_{2}$ phase, and $\mathrm{Al}-\mathrm{Zr}$ and $\mathrm{Al}-\mathrm{Cu}$ particles have been identified as the $\mathrm{Al}_{3} \mathrm{Zr}$ and $\mathrm{Al}_{2} \mathrm{Cu}$ phases. In the FEZ, the $\mathrm{Al}_{3} \mathrm{Zr}$ and $\mathrm{Al}_{60} \mathrm{Mn}_{11} \mathrm{Ni}_{4}$ precipitates are found both at the center of Aluminium grains and at the grain boundaries. The $\mathrm{Al}_{3} \mathrm{Zr}$ precipitates at the grains center have a cube-cube orientation relationship with the matrix whereas no orientation relationship has been established between the matrix and the $\mathrm{Al}_{60} \mathrm{Mn}_{11} \mathrm{Ni}_{4}$ particles but this would require further investigation because of the low symmetry of their structure. Regardless of the studied zone, $\mathrm{Al}_{9} \mathrm{Ni}_{2}, \mathrm{Al}_{3} \mathrm{Ni}_{2}$ and $\mathrm{Al}_{2} \mathrm{Cu}$ particles are found in the intergranular or interdendritic regions. Finally, the content of Manganese and Zirconium in the aluminium solid solution is higher in the columnar zone than in the fine equiaxed zone.

\section{Discussion}

\subsection{Solidification sequence in the FEZ}

The differences between the microstructures in FEZ and CZ will be discussed in section 4.2. Here, to get some insights regarding the spatial distribution of the various identified phases revealed by our multiscale investigation, in particular in the FEZ, thermodynamic solidification calculations have been run using Thermo-Calc with the database dedicated to Al-alloys (TCAL6 version 6.0), see Figure 11. Calculations have been run using both the equilibrium and Scheil-Gulliver models by considering only phases that have been observed experimentally. Note that these approaches do not give very different results except during the last stages of solidification, typically for solid fraction $f_{s}>0.9$. The ScheilGulliver assumptions, namely infinite diffusion in the liquid, no diffusion in the solid and equilibrium at the solid/liquid interface are thought to be closer to the processing conditions of L-PBF. One should be aware that the Scheil-Gulliver model suffers from several limitations. It does not take into account possible back-diffusion of solutes in the solid during solidification but this was neglected based on the fast-cooling rate of L-PBF and also on the fact that some of the solutes $(\mathrm{Zr}, \mathrm{Mn})$ are slow diffusers in aluminium. More importantly, it neglects solute trapping although it can play a key role in the solidification sequence. However, in the FEZ, unlike the CZ, it has been observed that solute enrichment in the FCC-aluminium phase does not seem to be significant, see Figure 7d-h and Figure S6. Thus, we still think that the Scheil model can be helpful to improve our understanding of the as-built microstructure, especially in the FEZ. 


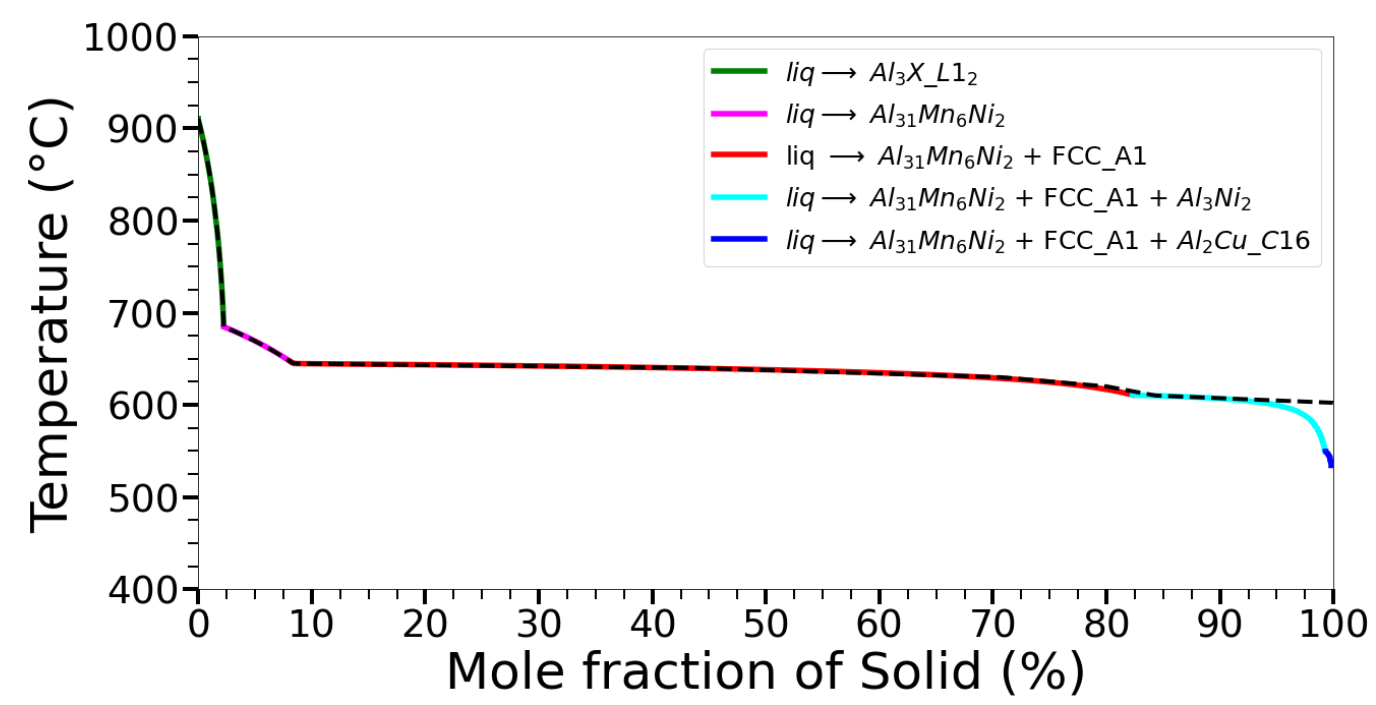

Figure 11: Solidification path computed with Thermo-Calc and the TCAL6 database, using both the equilibrium (black dotted line) and Scheil-Gulliver models. The solidification path was calculated retaining only the phases identified experimentally. The $\mathrm{Al}_{3} \mathrm{X}, \mathrm{Al}_{31} \mathrm{Mn}_{11} \mathrm{Ni}_{4}, \mathrm{FCC} \mathrm{Al}_{-}, \mathrm{Al}_{3} \mathrm{Ni}_{2}$ and $\mathrm{Al}_{2} \mathrm{Cu} \mathrm{C}_{-} \mathrm{Cl} 6$ described in the TCAL6 database correspond respectively to the $\mathrm{Al}_{3} \mathrm{Zr}$ $\mathrm{L1}_{2}$, Al $60 \mathrm{Mn}{ }_{11} \mathrm{Ni}$, FCC-Al matrix, $\mathrm{Al}_{3} \mathrm{Ni}_{2}$, and $\mathrm{Al}_{2} \mathrm{C}$ u phases identified experimentally. All transformations calculated with the Scheil-Gulliver model are reported in the figure.

From Figure 11, it can be seen that both the $\mathrm{L}_{2}-\mathrm{Al}_{3} \mathrm{Zr}$ and $\mathrm{Al}_{60} \mathrm{Mn}_{11} \mathrm{Ni}_{4}$ nucleating respectively in the liquid at $910^{\circ} \mathrm{C}$ and $685^{\circ} \mathrm{C}$ can be considered as primary phases as they form prior to the FCC-Al matrix. This is consistent with our observations showing the presence of $\mathrm{Al}_{3} \mathrm{Zr}$ square-shape particles or $\mathrm{Al}_{60} \mathrm{Mn}_{11} \mathrm{Ni}_{4}$ precipitates at the grain center in the FEZ. Interestingly, we found more systematically the presence of $\mathrm{Al}_{3} \mathrm{Zr}$ in the core of the grains than $\mathrm{Al}_{60} \mathrm{Mn}_{11} \mathrm{Ni}_{4}$ precipitates. Since both phases nucleate in the liquid before the FCC-Al matrix, they can both promote heterogeneous nucleation of the FCC-Al grains. The positive role of the $\mathrm{L}_{2}-\mathrm{Al}_{3} \mathrm{Zr}$ precipitates as a nucleating agent, already reported in [15] and [27], is confirmed here by the cube-cube orientation relationship with the matrix (Figure 8(a-d)) by taking advantage of the ACOM technique. We also found a few cases where the complex orthorhombic $\mathrm{Al}_{60} \mathrm{Mn}_{11} \mathrm{Ni}_{4}$ precipitates with a regular morphology are present at the core of aluminium grains, which strongly suggests that it also contributes to the nucleation of grains in the FEZ, see typically Figure 9c. However, the $\mathrm{L}_{2}-\mathrm{Al}_{3} \mathrm{Zr}$ phase is likely a more efficient nucleating agent because of the match between the $\mathrm{L}_{2}$ structure and the FCC structure of $\mathrm{Al}$, together with a very small lattice misfit [41].

\begin{tabular}{ccccccc}
\hline Temperature $\left({ }^{\circ} \mathrm{C}\right)$ & $\begin{array}{c}\mathrm{Al}_{3} \mathrm{Zr} \\
\mathrm{L}_{2}\end{array}$ & $\mathrm{Al}_{31} \mathrm{Mn}_{6} \mathrm{Ni}_{2}$ & $\mathrm{FCC}_{-} \mathrm{A} 1$ & $\mathrm{Al}_{3} \mathrm{Ni}_{2}$ & $\begin{array}{c}\mathrm{Al}_{2} \mathrm{Cu} \\
\mathrm{C} \_16\end{array}$ & Liquid \\
\hline$@ 685^{\circ} \mathrm{C}$ & 2.25 & & & & & 97.75 \\
\hline$@ 645^{\circ} \mathrm{C}$ & 2.37 & 5.91 & & & & 91.72 \\
\hline$@ 610^{\circ} \mathrm{C}$ & 2.37 & 9.88 & 70.11 & & 17.65 \\
\hline$@ 597^{\circ} \mathrm{C}$ & 2.37 & 10.05 & 72.85 & & & 14.74 \\
\hline$@ 549^{\circ} \mathrm{C}$ & 2.37 & 10.06 & 82.68 & 4.15 & & 0.74 \\
\hline$@ 534^{\circ} \mathrm{C}$ & 2.37 & 10.08 & 82.95 & 4.15 & 0.26 & 0.19 \\
\hline
\end{tabular}

Table 2: The molar fraction of phases in percent at different temperatures according to the Scheil-Gulliver model.

These two primary phases have also been identified in the interdendritic regions. The presence of intergranular $\mathrm{Al}_{60} \mathrm{Mn}_{11} \mathrm{Ni}_{4}$ particles can be rationalized with the help of our thermodynamic calculations shown in Figure 11. Indeed, the Scheil computation predicts that the $\mathrm{Al}_{60} \mathrm{Mn}_{11} \mathrm{Ni}_{4}$ phase precipitates as a primary phase in the liquid as well as later during the solidification sequence. As shown in Table 2, 
the total equilibrium molar fraction of this phase is about $10 \%$ : the first $6 \%$ of this phase stems from its precipitation as a primary phase while the remaining $4 \%$ solidifies simultaneously or after the Al-matrix. This turns out to be also in relatively good agreement with the morphology of some of the $\mathrm{Al}_{60} \mathrm{Mn}_{11} \mathrm{Ni}_{4}$ precipitates. This is exemplified in Figure 8a or Figure S5a where some of the $\mathrm{Al}_{60} \mathrm{Mn}_{11} \mathrm{Ni}_{4}$ precipitates fill the interdendritic space. On the contrary, the presence of the small $\mathrm{Al}_{3} \mathrm{Zr}$ precipitates exhibiting an ill-defined morphology as typically illustrated in Figure 8e in the interdendritic regions cannot be captured by our predictions. Their size, typically about $50 \mathrm{~nm}$, and their morphology rather suggest that these particles precipitate during the last stages of solidification. Complementary observations shown in 5a have also revealed the presence of square-shape $\mathrm{Al}_{3} \mathrm{Zr}$ precipitates in the vicinity of the grain boundaries. The latter observation leads us to suggest that some of the primary $\mathrm{Al}_{3} \mathrm{Zr}$ precipitates do not systematically act as a nucleating agent for the FCC-Al grains but could in some cases be pushed towards the interdendritic regions by the solid/liquid interface during solidification.

The interdendritic regions are also decorated by three additional secondary phases: $\mathrm{Al}_{9} \mathrm{Ni}_{2}, \mathrm{Al}_{3} \mathrm{Ni}_{2}$ and $\mathrm{Al}_{2} \mathrm{Cu}$ present in different proportions (Figure S5). The Scheil-Gulliver model shown in Figure 11 only predicts the formation of $\mathrm{Al}_{3} \mathrm{Ni}_{2}$ (about $4 \%$ molar fraction, see Table 2 ) at $610^{\circ} \mathrm{C}$ and $\mathrm{Al}_{2} \mathrm{Cu}($ about $0.26 \%$ molar fraction, see Table 2 ) at $550^{\circ} \mathrm{C}$. In contrast with these thermodynamic calculations, our microstructural investigations have shown the presence of $\mathrm{Al}_{9} \mathrm{Ni}_{2}$ and its proportion is clearly higher than the proportion of $\mathrm{Al}_{3} \mathrm{Ni}_{2}$. In the literature [38] and [42], it is suggested that the $\mathrm{Al}_{9} \mathrm{Ni}_{2}$ phase can be considered as metastable while the stable phase is thought to be $\mathrm{Al}_{3} \mathrm{Ni}_{2}$. We believe that the $\mathrm{Al}_{9} \mathrm{Ni}_{2}$ is in larger proportion in the as-built microstructure than the $\mathrm{Al}_{3} \mathrm{Ni}_{2}$ phase because L-PBF occurs under outof-equilibrium conditions, promoting a phase with a better crystallographic matching with $\mathrm{Al}$ and/or a lower interfacial energy.

\subsection{Hierarchical nature of the microstructure}

To get a better understanding of the hierarchical nature of the as-built microstructure, especially at the melt pool scale with the three different zones FEZ, CZ and CEZ, we will now discuss the solidification mechanisms within the melt pool. Due to the geometry of the melt pool and the gaussian distribution of the heat input, the solidification rate increases when getting closer to the top or center of the melt pool [31]. In other words, the lowest solidification rates are expected at the melt pool bottom. Thus, primary intermetallic phases such as $\mathrm{Al}_{3} \mathrm{Zr}$ have more time to nucleate from the liquid and grow in this region as explained by Griffiths in [31], and revealed by the ACOM/EDS coupling in the FEZ (Figure 7-9). In addition to $\mathrm{Al}_{3} \mathrm{Zr}$, we have reported a few cases where the $\mathrm{Al}_{60} \mathrm{Mn}_{11} \mathrm{Ni}_{4}$ primary phase acts also potentially as nucleating agent. These two inoculant phases are responsible for the presence of submicronic grains in the FEZ at the melt pool bottom. The proportion of the FEZ relatively to the CZ is larger comparatively to what is reported other studies, see e.g. [9], [16]. This is in agreement with the results published in [32] that showed that the fraction of the FEZ can be tailored by controlling the preheating temperature. The authors of this study suggest that the fraction of the FEZ can be increased by increasing the temperature of the build substrate from 35 to $200^{\circ} \mathrm{C}$. We recall here that in our study the samples were produced using a build substrate temperature of $200^{\circ} \mathrm{C}$. The presence of this FEZ also prevents the epitaxial growth of columnar grains from the underlying layers. This explains the absence of elongated columnar grains with a length of several hundreds of micrometres crossing several melt pools, a situation that is known to be promote hot cracks development. The relatively slow solidification rate (speed of the solidification front) in this region can also explain the low content of alloying elements retained in the FCC-Al matrix in comparison with the CZ, suggested from EDS maps and consistent with the profuse precipitation of the various secondary phases from the solute enriched liquid. When a critical solidification rate is exceeded, the primary phases, namely $\mathrm{Al}_{3} \mathrm{Zr}$ and $\mathrm{Al}_{60} \mathrm{Mn}_{11} \mathrm{Ni}_{4}$, do not have enough time to nucleate from the liquid. In addition, solute trapping is expected to occur, with solutes such as $\mathrm{Zr}$ and $\mathrm{Mn}$ being retained in the FCC-Al dendrites, thus reducing the fraction of intermetallic 
phases found in the interdendritic regions of the $\mathrm{CZ}$ when compared to those in the FEZ. This absence of nucleating agent accounts for the transition from equiaxed grains in the FEZ to columnar grains in the $\mathrm{CZ}$. The higher solid/liquid interface velocity in the $\mathrm{CZ}$ also rationalizes the smaller size of the intermetallic particles, which form after the matrix and have a very short time to grow compared to those in the FEZ.

As already reported for others aluminium alloys fabricated by L-PBF (Al-Mg-Si-Sc-Zr [25], Al-Mg-Zr [32]), the microstructure of the investigated alloy presents a regular arrangement of its microstructure induced by the juxtaposition and stacking of the different melt pools (Figure 1b). At the melt pool scale, we show that the microstructure is divided in three zones (FEZ, CZ, CEZ) giving a hierarchical nature to the microstructure. However, in contrast with the cases reported in the literature (Al-Mg-Zr [12], [15], or Al-Mn-Sc [43]), we did not observed a periodic arrangement of these zones at a multilayer scale (Figure 2). We also revealed the presence of a CEZ that seems to be an additional specific feature of this $\mathrm{Al}-4 \mathrm{Mn}-3 \mathrm{Ni}-2 \mathrm{Cu}-1 \mathrm{Zr}$ processed by L-PBF because the presence of coarse equiaxed grains in $\mathrm{Al}-$ alloys modified with $\mathrm{Zr} / \mathrm{Sc}$ additions has rarely been reported. The presence of narrow bands consisting of fine equiaxed grains at the center of the melt pools can be seen as the microstructural signature of the presence of convective flows. Those convective flows induced by the Marangoni effect and the recoil pressure [44] are thought to be the mechanisms at the origin of those fine equiaxed grain stripes observed in the melt pool center as shown schematically in Figure 12a-b. Such fine equiaxed grain stripes have not been experimentally evidenced yet in Al-alloys processed by AM, though they are likely to occur because they were produced using very similar processing conditions. Here, we believe that convective flows leave a microstructural signature due to an increased melt viscosity caused by the introduction of various solutes in relatively large amount. Convection during solidification might lead to the transportation of primary phases acting as nucleating agents or of fine equiaxed grains already nucleated in the liquid. The primary phases or small equiaxed grains are thought to be pulled away from the melt pool boundary to the central upper part of the melt pool following the direction of the convective flows, see blue arrows in Figure 1b). Because of the variations of solidification rate within the melt pool [45], the number of primary $\mathrm{Al}_{3} \mathrm{Zr}$ acting as nucleating agents decreases when getting closer to the top most part of the melt pool where the solidification rate is higher than in the vicinity of the melt pool boundary. Thus, according to the number of nucleation sites, the grain size is smaller in the FEZ than in the CEZ where there are fewer primary phases in the liquid. This scenario helps to rationalize both the presence of narrow stripes of equiaxed grains in the melt pool center and the CEZ at the melt pool top. The latter scenario is supported by microstructural observations showing (i) the presence of the presence of narrow bands of fine equiaxed grains in unexpected regions of the melt pools (Figure 12c); and (ii) the presence of primary $\mathrm{Al}_{3} \mathrm{Zr}$ precipitates in the core of coarse equiaxed grains located in the top region of the melt pools, see Figure 12d.

Another mechanism could be invoked: the possible break of dendrite tips that can also lead to additional nucleation sites. However, the recent study from Du et al [46] shows that the impact of convection in the liquid is likely not sufficient to break the dendrite tips but an additional magnetic field is needed to do so. Another scenario was proposed by Yang et al. [32] based on the distribution of the thermal gradient to growth rate ratio in order to explain the formation of coarse equiaxed grains in the melt pool. Though this scenario does not take into account convective flows and therefore does not explain the presence of the narrow bands of equiaxed grains observed in the present work, this can contribute to the formation of coarse equiaxed grains (CEZ). Finally, these three zones and their distribution are involved in the mitigation of hot cracking by avoiding the growth of coarse columnar grains along the build direction, see Zhou et al. [47]. Convection also helps to randomize the texture, avoiding the strong textures typical of AM parts with coarse columnar structures. The supersaturated solute content retained in the FCC-Al dendrites of the $\mathrm{CZ}$, especially $\mathrm{Mn}$ and $\mathrm{Zr}$ is the source of age hardening potential in this system. 

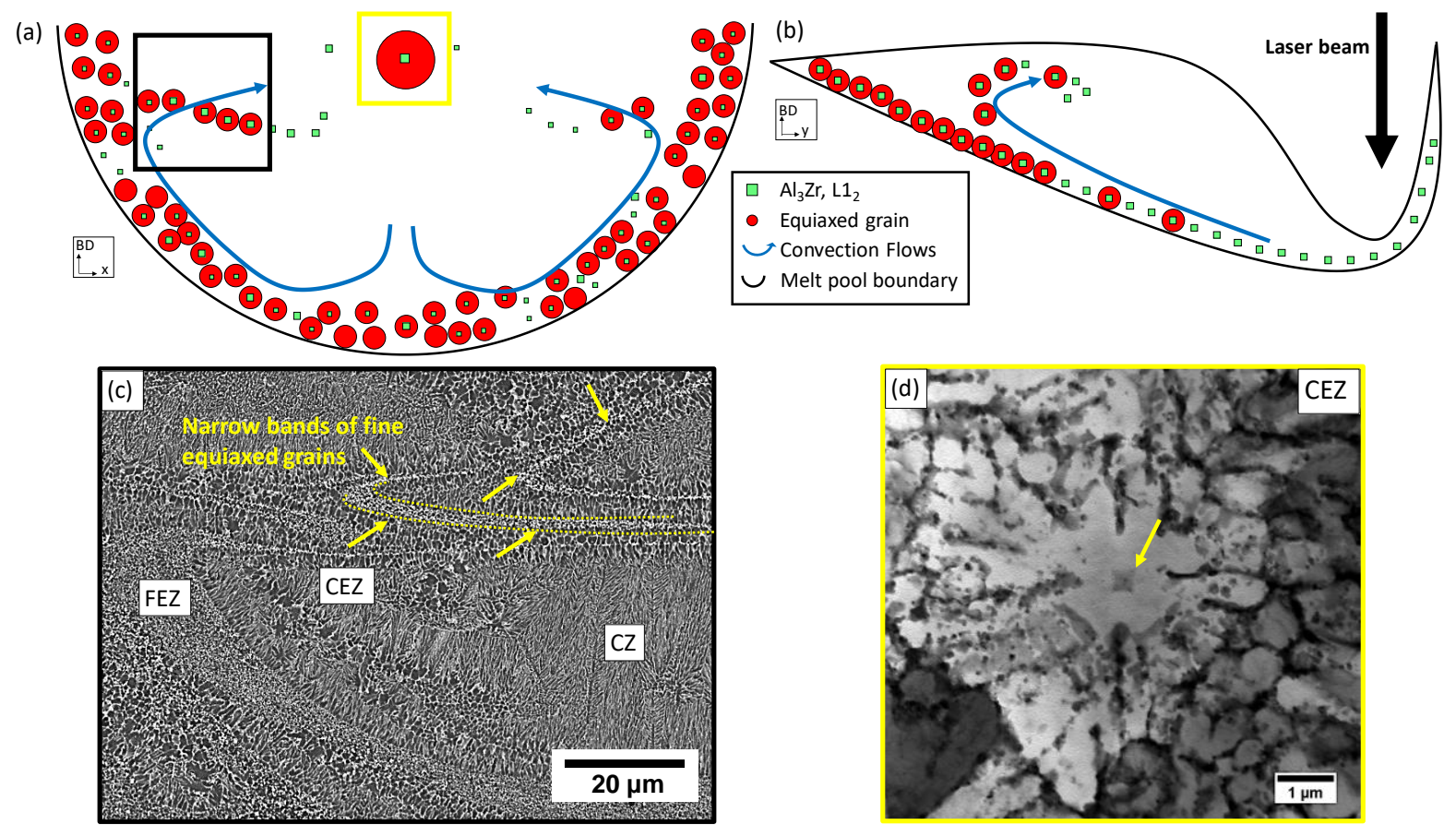

Figure 12: Schematic illustrating the effect of convective flows induced by Marangoni flows and recoil pressure to rationalize the presence of the coarse equiaxed grains at the melt pool top: $(a)$ in the XZ-plane and $(b)$ in the YZ-plane. Convective flows are indicated using blue arrows. The AlsZr primary phase acting as a nucleation agent or small equiaxed grains are transported by the convection in the molten metal.

Finally, we would like to comment on the peculiar morphology of the dendrites in the $\mathrm{CZ}$ as well as on the presence of some twinned dendrites (see example in Figure 4c-d). This unusual palm-tree like morphology of dendrites in FCC-metals has already been reported in some cases [35], [36], [48]. The recent viewpoint paper published by Rappaz et al. [36] suggests that our observations are consistent with possible Icosahedral Short Range Order (ISRO) of the atoms in the liquid. Experimental evidence has been provided in favor of this hypothesis that icosahedral quasicrystal (iQC-) mediated nucleation could trigger twinned dendrites growth in some Al-alloys [48], [49]. ISRO is also known to reduce the mobility of transition metal atoms in liquid aluminium through a cage effect, thus promoting solute trapping. We plan to further evaluate the contribution of ISRO to the solidification behavior of the investigated material.

\section{Summary and Conclusions}


A novel Al-Mn-Ni-Cu-Zr alloy has been successfully processed by L-PBF fabricated, for which hot cracking has been mitigated thanks to grain refinement. In this report we have analyzed in details the microstructure at various scales and studied the links between the processing conditions typical of L$\mathrm{PBF}$ and the peculiarities of the inherited microstructure in this new alloy. The following specific conclusions have been drawn:

- The grain structure inherited from L-PBF is very complex and three different regions have been identified based on the grain size and morphology, namely the fine equiaxed zone (FEZ), columnar zone (CZ) and coarse equiaxed zone (CEZ). The arrangement of these three zones gives a hierarchical character to the microstructure.

- A substantial fraction of second phase particles, more than $20 \%$, was found in the microstructure.

- The spatial distribution, nature and morphology of the second phase particles were found to vary within a given molten pool depending on the region selected: FEZ, CZ or CEZ. Slow diffuser species such as $\mathrm{Zr}$ and $\mathrm{Mn}$ are retained in solid solution in FCC-Al in larger amount in the $\mathrm{CZ}$ in comparison with the FEZ. This could be a source of further age hardening in this system. The differences evidenced between the various regions in a given molten pool have been attributed to (i) variations of the solidification conditions, especially the solidification rate at the melt pool scale; and (ii) to the presence of convective flows that is believed to transport grains or primary phases acting as nucleating agents.

- Five different secondary phases were identified, most of them being unreported yet in AM products: $\mathrm{Al}_{3} \mathrm{Ni}_{2}, \mathrm{Al}_{9} \mathrm{Ni}_{2}$, and $\mathrm{Al}_{60} \mathrm{Mn}_{11} \mathrm{Ni}_{4}$.

- In the FEZ, grain refinement was mainly caused by the formation of the metastable $\mathrm{Al}_{3} \mathrm{Zr}_{\mathrm{r}} \mathrm{L}_{12}$ primary phase but the $\mathrm{Al}_{60} \mathrm{Mn}_{11} \mathrm{Ni}_{4}$ that contains local icosahedral packing seems also to contribute to promote the nucleation of FCC-Al grains.

- Among the identified phases, two of them, the ones being in the largest fraction namely the $\mathrm{Al}_{9} \mathrm{Ni}_{2}$ and the $\mathrm{Al}_{60} \mathrm{Mn}_{11} \mathrm{Ni}_{4}$ are crystals with large lattice parameters, a characteristic that is known to be beneficial for the thermal stability and that was initially intentionally targeted, thus bringing a first validation of our alloy design strategy.

The relationships between this peculiar microstructure and the mechanical properties at room temperature up to $200-250^{\circ} \mathrm{C}$ are currently under investigation.

\section{Acknowledgements}

The authors thank Constellium for the financial support of this work. Philippe JARRY from Constellium is gratefully acknowledged for fruitful discussions.

\section{References}

[1] T. DebRoy et al., « Additive manufacturing of metallic components - Process, structure and properties », Progress in Materials Science, vol. 92, p. 112-224, mars 2018, doi: 10.1016/j.pmatsci.2017.10.001.

[2] X. P. Li et al., «A selective laser melting and solution heat treatment refined Al-12Si alloy with a controllable ultrafine eutectic microstructure and 25\% tensile ductility », Acta Materialia, vol. 95, p. 74-82, août 2015, doi: 10.1016/j.actamat.2015.05.017.

[3] L. Thijs, K. Kempen, J.-P. Kruth, et J. Van Humbeeck, « Fine-structured aluminium products with controllable texture by selective laser melting of pre-alloyed AlSi10Mg powder », Acta Materialia, vol. 61, n 5, p. 1809-1819, mars 2013, doi: 10.1016/j.actamat.2012.11.052. 
[4] K. G. Prashanth, S. Scudino, et J. Eckert, « Defining the tensile properties of Al-12Si parts produced by selective laser melting », Acta Materialia, vol. 126, p. 25-35, mars 2017, doi: 10.1016/j.actamat.2016.12.044.

[5] S. Z. Uddin, L. E. Murr, C. A. Terrazas, P. Morton, D. A. Roberson, et R. B. Wicker, «Processing and characterization of crack-free aluminum 6061 using high-temperature heating in laser powder bed fusion additive manufacturing », Additive Manufacturing, vol. 22, p. 405-415, août 2018, doi: 10.1016/j.addma.2018.05.047.

[6] W. Stopyra, K. Gruber, I. Smolina, T. Kurzynowski, et B. Kuźnicka, « Laser powder bed fusion of AA7075 alloy: Influence of process parameters on porosity and hot cracking », Additive Manufacturing, vol. 35, p. 101270, oct. 2020, doi: 10.1016/j.addma.2020.101270.

[7] A. Sonawane, G. Roux, J.-J. Blandin, A. Despres, et G. Martin, « Cracking mechanism and its sensitivity to processing conditions during laser powder bed fusion of a structural Aluminum alloy. », Materialia, p. 100976, déc. 2020, doi: 10.1016/j.mtla.2020.100976.

[8] T. M. Pollock, J. Martin, B. D. Yahata, J. M. Hundley, J. A. Mayer, et T. A. Schaedler, « 3D printing of high-strength aluminium alloys », Nature, vol. 549, p. 365-369, 2017.

[9] M. Opprecht, J.-P. Garandet, G. Roux, C. Flament, et M. Soulier, « A solution to the hot cracking problem for aluminium alloys manufactured by laser beam melting », Acta Materialia, vol. 197, p. 40-53, sept. 2020, doi: 10.1016/j.actamat.2020.07.015.

[10] M. L. Montero-Sistiaga et al., « Changing the alloy composition of Al7075 for better processability by selective laser melting », Journal of Materials Processing Technology, vol. 238, p. 437-445, déc. 2016, doi: 10.1016/j.jmatprotec.2016.08.003.

[11] Y. Otani et S. Sasaki, «Effects of the addition of silicon to 7075 aluminum alloy on microstructure, mechanical properties, and selective laser melting processability », Materials Science and Engineering: A, vol. 777, p. 139079, mars 2020, doi: 10.1016/j.msea.2020.139079.

[12] L. Zhou et al., « Microstructure and mechanical properties of Zr-modified aluminum alloy 5083 manufactured by laser powder bed fusion », Additive Manufacturing, vol. 28, p. 485-496, août 2019, doi: 10.1016/j.addma.2019.05.027.

[13] H. Zhang, H. Zhu, X. Nie, J. Yin, Z. Hu, et X. Zeng, « Effect of Zirconium addition on crack, microstructure and mechanical behavior of selective laser melted $\mathrm{Al}-\mathrm{Cu}-\mathrm{Mg}$ alloy », Scripta Materialia, vol. 134, p. 6-10, juin 2017, doi: 10.1016/j.scriptamat.2017.02.036.

[14] A. B. Spierings et al., « Microstructural features of Sc- and Zr-modified Al-Mg alloys processed by selective laser melting », Materials \& Design, vol. 115, p. 52-63, févr. 2017, doi: 10.1016/j.matdes.2016.11.040.

[15] J. R. Croteau et al., « Microstructure and mechanical properties of Al-Mg-Zr alloys processed by selective laser melting », Acta Materialia, vol. 153, p. 35-44, juill. 2018, doi: 10.1016/j.actamat.2018.04.053.

[16] R. Li, M. Wang, Z. Li, P. Cao, T. Yuan, et H. Zhu, « Developing a high-strength Al-Mg-Si-Sc$\mathrm{Zr}$ alloy for selective laser melting: Crack-inhibiting and multiple strengthening mechanisms », Acta Materialia, vol. 193, p. 83-98, juill. 2020, doi: 10.1016/j.actamat.2020.03.060.

[17] Q. Jia et al., « Selective laser melting of a high strength AlMnSc alloy: Alloy design and strengthening mechanisms », Acta Materialia, vol. 171, p. 108-118, juin 2019, doi: 10.1016/j.actamat.2019.04.014.

[18] Q. Jia et al., «Precipitation kinetics, microstructure evolution and mechanical behavior of a developed Al-Mn-Sc alloy fabricated by selective laser melting », Acta Materialia, vol. 193, p. 239-251, juill. 2020, doi: 10.1016/j.actamat.2020.04.015.

[19] « ISO 6892-1:2019(fr), Matériaux métalliques — Essai de traction — Partie 1: Méthode d'essai à température ambiante ». https://www.iso.org/obp/ui\#iso:std:iso:6892:-1:ed-3:v1:fr (consulté le déc. 03, 2020).

[20] E. F. Rauch et M. Véron, « Automated crystal orientation and phase mapping in TEM », Materials Characterization, vol. 98, p. 1-9, déc. 2014, doi: 10.1016/j.matchar.2014.08.010.

[21] H. Zhang, H. Zhu, T. Qi, Z. Hu, et X. Zeng, « Selective laser melting of high strength Al-CuMg alloys: Processing, microstructure and mechanical properties », Materials Science and Engineering: A, vol. 656, p. 47-54, févr. 2016, doi: 10.1016/j.msea.2015.12.101. 
[22] N. O. Larrosa et al., «Linking microstructure and processing defects to mechanical properties of selectively laser melted AlSi10Mg alloy », Theoretical and Applied Fracture Mechanics, vol. 98, p. 123-133, déc. 2018, doi: 10.1016/j.tafmec.2018.09.011.

[23] H. Rao, S. Giet, K. Yang, X. Wu, et C. H. J. Davies, « The influence of processing parameters on aluminium alloy A357 manufactured by Selective Laser Melting », Materials \& Design, vol. 109, p. 334-346, nov. 2016, doi: 10.1016/j.matdes.2016.07.009.

[24] M. Wang et al., « Microstructures and mechanical property of AlMgScZrMn - A comparison between selective laser melting, spark plasma sintering and cast », Materials Science and Engineering: A, vol. 756, p. 354-364, mai 2019, doi: 10.1016/j.msea.2019.04.060.

[25] J. Bi et al., «An additively manufactured Al-14.1Mg-0.47Si-0.31 Sc-0.17Zr alloy with high specific strength, good thermal stability and excellent corrosion resistance », Journal of Materials Science \& Technology, vol. 67, p. 23-35, mars 2021, doi: 10.1016/j.jmst.2020.06.036.

[26] L. Zhou et al., « Microstructure and tensile property of a novel AlZnMgScZr alloy additively manufactured by gas atomization and laser powder bed fusion », Scripta Materialia, vol. 158, p. 24-28, janv. 2019, doi: 10.1016/j.scriptamat.2018.08.025.

[27] X. Nie, H. Zhang, H. Zhu, Z. Hu, L. Ke, et X. Zeng, « Effect of Zr content on formability, microstructure and mechanical properties of selective laser melted $\mathrm{Zr}$ modified $\mathrm{Al}-4.24 \mathrm{Cu}-$ $1.97 \mathrm{Mg}-0.56 \mathrm{Mn}$ alloys », Journal of Alloys and Compounds, vol. 764, p. 977-986, oct. 2018, doi: 10.1016/j.jallcom.2018.06.032.

[28] T. Qi, H. Zhu, H. Zhang, J. Yin, L. Ke, et X. Zeng, « Selective laser melting of Al7050 powder: Melting mode transition and comparison of the characteristics between the keyhole and conduction mode », Materials \& Design, vol. 135, p. 257-266, déc. 2017, doi: 10.1016/j.matdes.2017.09.014.

[29] Z. Hu, H. Zhang, H. Zhu, Z. Xiao, X. Nie, et X. Zeng, « Microstructure, mechanical properties and strengthening mechanisms of AlCu5MnCdVA aluminum alloy fabricated by selective laser melting », Materials Science and Engineering: A, vol. 759, p. 154-166, juin 2019, doi: 10.1016/j.msea.2019.04.114.

[30] J. Wu, X. Q. Wang, W. Wang, M. M. Attallah, et M. H. Loretto, « Microstructure and strength of selectively laser melted AlSi10Mg », Acta Materialia, vol. 117, p. 311-320, sept. 2016, doi: 10.1016/j.actamat.2016.07.012.

[31] S. Griffiths, M. D. Rossell, J. Croteau, N. Q. Vo, D. C. Dunand, et C. Leinenbach, « Effect of laser rescanning on the grain microstructure of a selective laser melted $\mathrm{Al}-\mathrm{Mg}-\mathrm{Zr}$ alloy », Materials Characterization, vol. 143, p. 34-42, sept. 2018, doi: 10.1016/j.matchar.2018.03.033.

[32] K. V. Yang, Y. Shi, F. Palm, X. Wu, et P. Rometsch, « Columnar to equiaxed transition in Al$\mathrm{Mg}(-\mathrm{Sc})-\mathrm{Zr}$ alloys produced by selective laser melting », Scripta Materialia, vol. 145, p. 113-117, mars 2018, doi: 10.1016/j.scriptamat.2017.10.021.

[33] X. Liu, C. Zhao, X. Zhou, Z. Shen, et W. Liu, « Microstructure of selective laser melted AlSi10Mg alloy », Materials \& Design, vol. 168, p. 107677, avr. 2019, doi: 10.1016/j.matdes.2019.107677.

[34] L. Xi et al., «Effect of TiB2 particles on microstructure and crystallographic texture of Al-12Si fabricated by selective laser melting », Journal of Alloys and Compounds, vol. 786, p. 551-556, mai 2019, doi: 10.1016/j.jallcom.2019.01.327.

[35] S. Henry, M. Rappaz, et P. Jarry, « 〈110〉 dendrite growth in aluminum feathery grains », Metall Mater Trans A, vol. 29, no 11, p. 2807-2817, nov. 1998, doi: 10.1007/s11661-998-0321-9.

[36] M. Rappaz, Ph. Jarry, G. Kurtuldu, et J. Zollinger, « Solidification of Metallic Alloys: Does the Structure of the Liquid Matter?», Metall Mater Trans A, vol. 51, nº 6, p. 2651-2664, juin 2020, doi: 10.1007/s11661-020-05770-9.

[37] P. Jarry et M. Rappaz, « Recent advances in the metallurgy of aluminium alloys. Part I: Solidification and casting », Comptes Rendus Physique, vol. 19, n 8, p. 672-687, déc. 2018, doi: 10.1016/j.crhy.2018.09.003.

[38] A. Ustinov et S. Demchenkov, «Influence of metastable A19Ni2 phase on the sequence of phase transformations initiated by heating of Al/Ni multilayer foils produced by EBPVD method », Intermetallics, vol. 84, p. 82-91, mai 2017.

[39] Katarzyna Stan-Glowinska, «Formation of Quasicrystalline Phases and Their Close Approximants in Cast Al-Mn Base Alloys Modified by Transition Metals ». 
[40] D. Eskin, «Ultrasonic processing of aluminium alloys above the liquidus: the role of $\mathrm{Zr}$ », MATEC Web Conf., vol. 326, p. 06002, 2020, doi: 10.1051/matecconf/202032606002.

[41] S. Saha, T. Z. Todorova, et J. W. Zwanziger, « Temperature dependent lattice misfit and coherency of $\mathrm{Al} 3 \mathrm{X}(\mathrm{X}=\mathrm{Sc}, \mathrm{Zr}, \mathrm{Ti}$ and $\mathrm{Nb})$ particles in an Al matrix », Acta Materialia, vol. 89, p. 109-115, mai 2015, doi: 10.1016/j.actamat.2015.02.004.

[42] A. Yanamoto et Tsubakino, «Al9Ni2 precipitates formed in an Al-Ni dilute alloy », Scripta Materialia, vol. 37, $\mathrm{n}^{\circ}$ 11, p. 1721-1725, déc. 1997, doi: 10.1016/S1359-6462(97)00329-1.

[43] Q. Jia, P. Rometsch, S. Cao, K. Zhang, et X. Wu, « Towards a high strength aluminium alloy development methodology for selective laser melting », Materials \& Design, vol. 174, p. 107775, juill. 2019, doi: 10.1016/j.matdes.2019.107775.

[44] S. A. Khairallah, A. T. Anderson, A. Rubenchik, et W. E. King, « Laser powder-bed fusion additive manufacturing: Physics of complex melt flow and formation mechanisms of pores, spatter, and denudation zones », Acta Materialia, vol. 108, p. 36-45, avr. 2016, doi: 10.1016/j.actamat.2016.02.014.

[45] M. J. Ansari, D.-S. Nguyen, et H. S. Park, « Investigation of SLM Process in Terms of Temperature Distribution and Melting Pool Size: Modeling and Experimental Approaches », Materials, vol. 12, $\mathrm{n}^{\circ}$ 8, Art. $\mathrm{n}^{\circ}$ 8, janv. 2019, doi: 10.3390/ma12081272.

[46] D. Du et al., «Influence of static magnetic field on microstructure and mechanical behavior of selective laser melted AlSi10Mg alloy », Materials \& Design, vol. 181, p. 107923, nov. 2019, doi: 10.1016/j.matdes.2019.107923.

[47] L. Zhou et al., « Microstructure and mechanical properties of Zr-modified aluminum alloy 5083 manufactured by laser powder bed fusion », Additive Manufacturing, vol. 28, p. 485-496, août 2019, doi: 10.1016/j.addma.2019.05.027.

[48] G. Kurtuldu, P. Jarry, et M. Rappaz, « Influence of Cr on the nucleation of primary Al and formation of twinned dendrites in $\mathrm{Al}-\mathrm{Zn}-\mathrm{Cr}$ alloys: Can icosahedral solid clusters play a role? », Acta Materialia, vol. 61, no 19, p. 7098-7108, nov. 2013, doi: 10.1016/j.actamat.2013.07.056.

[49] G. Kurtuldu, P. Jarry, et M. Rappaz, « Influence of icosahedral short range order on diffusion in liquids: A study on Al-Zn-Cr alloys », Acta Materialia, vol. 115, p. 423-433, août 2016, doi: 10.1016/j.actamat.2016.05.051. 


\section{SUPPLEMENTARY MATERIALS}

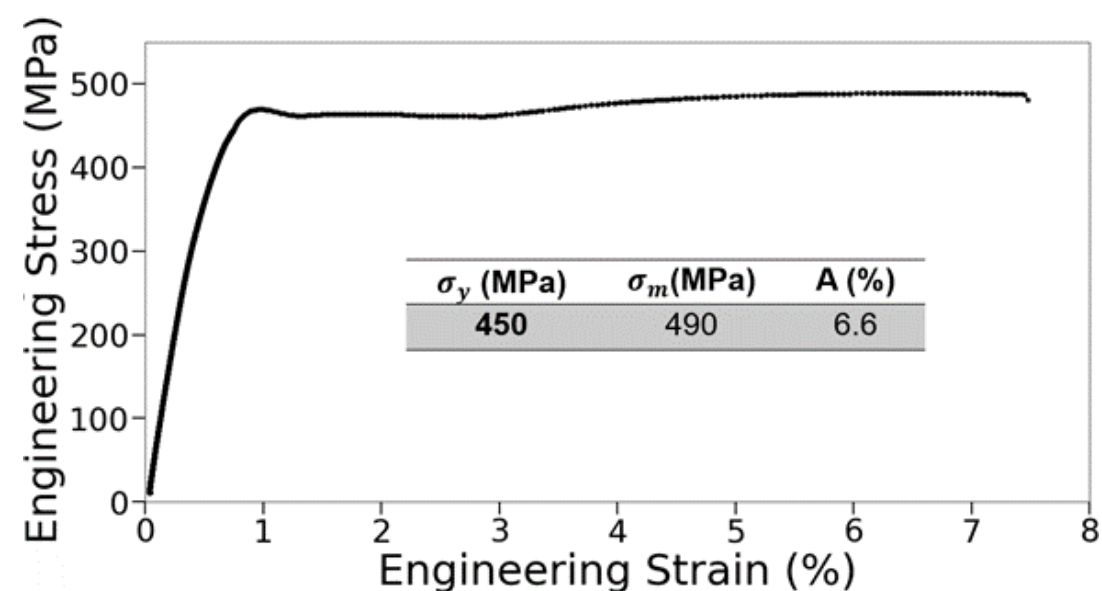

Figure S1: Engineering Stress-Strain curve of this new alloy along with the ultimate tensile strength (UTS), the plastic elongation to fracture and the yield strength. 

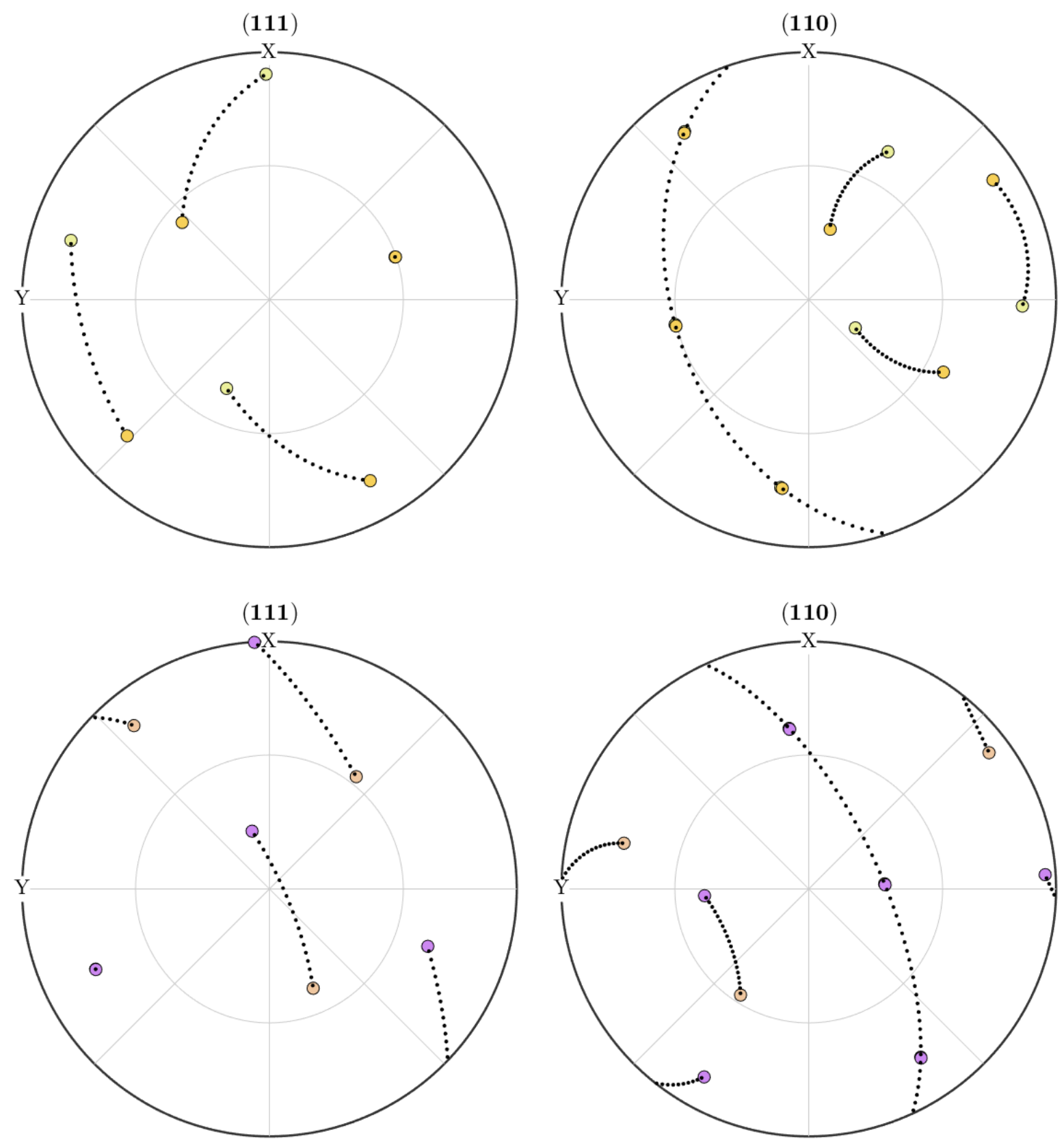

Figure S2: (111) and (110) pole figures showing a $\{111\}$ common plane with a $60^{\circ}$ rotation around a $\langle 111\rangle-$ direction. This indicates the presence of two twinned dendrites exhibited in Figure 3b-c. 


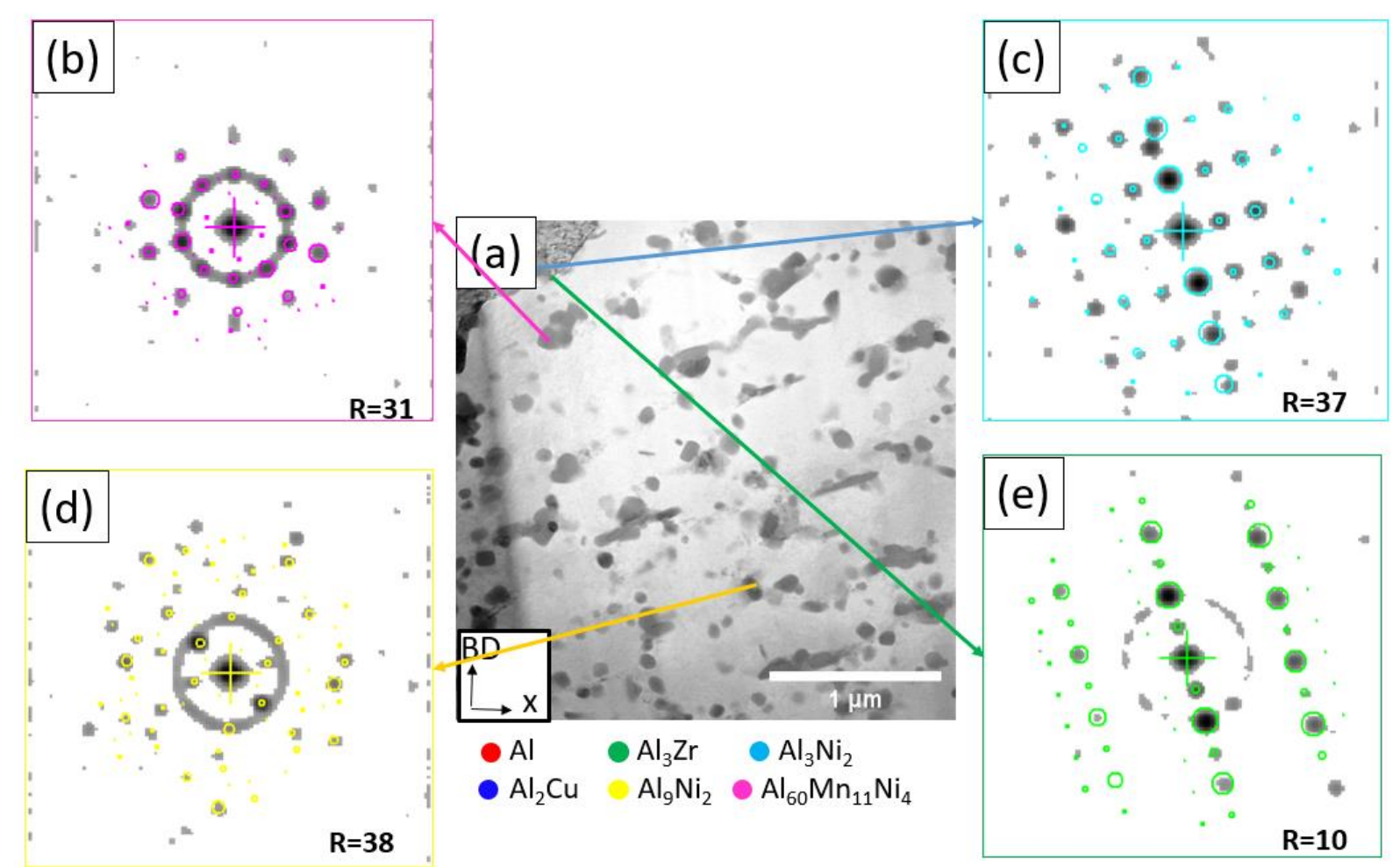

Figure S3: (a) Virtual Bright field of the columnar zone. (b-c-d-e) Experimental nanodiffraction patterns superimposed with the calculated diffraction patterns of the structures retrieved from the XRD pattern indexation (Figure 5): (b) Al6oMn ${ }_{11} N i 4$, , (c) $\mathrm{Al}_{3} \mathrm{Ni}_{2},(d) \mathrm{Al}_{9} \mathrm{Ni}_{2}$, and (e) $\mathrm{Al}_{3} \mathrm{Zr}$. The color code is the same as in Figure 5.
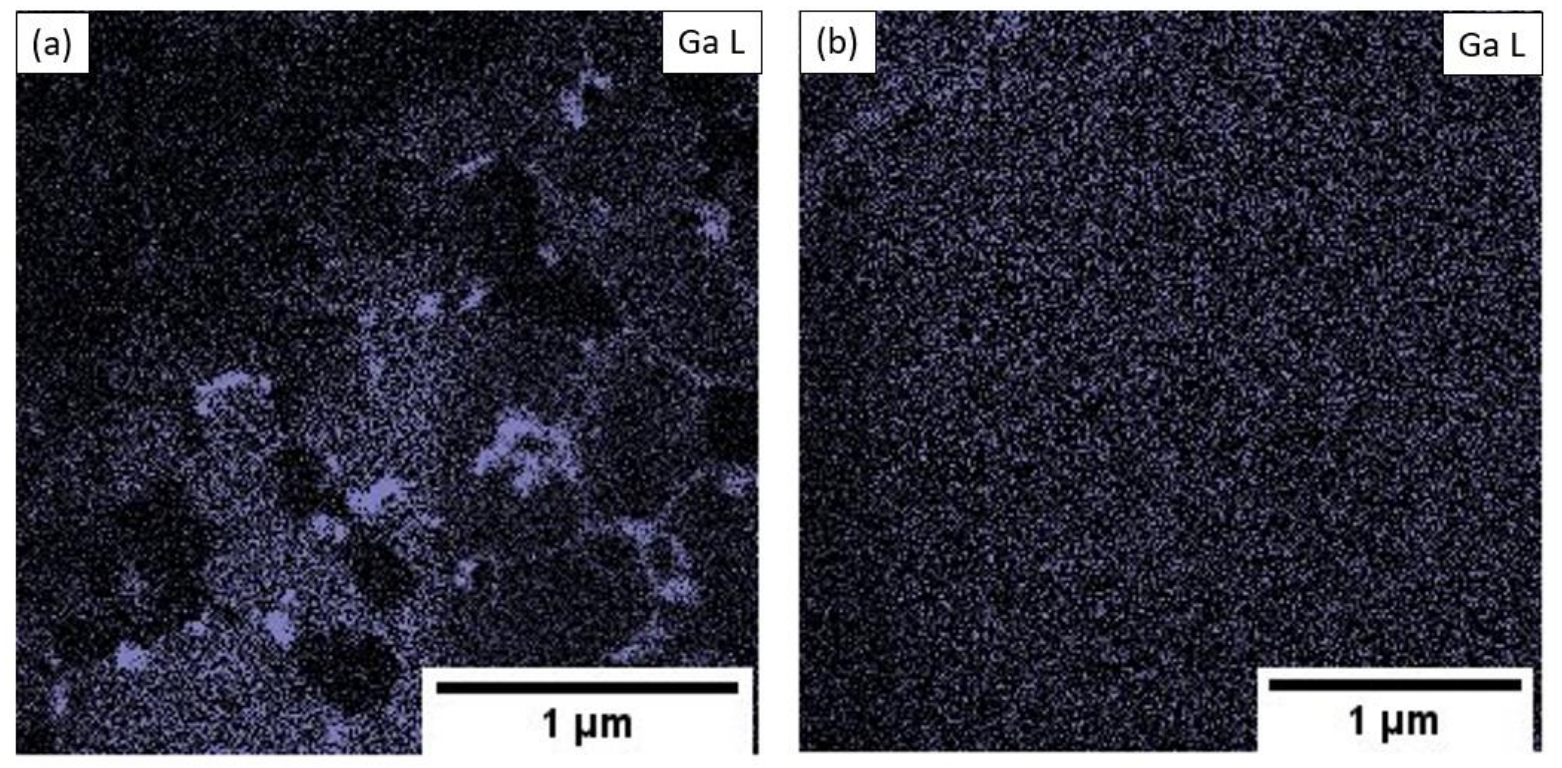

Figure S4: EDX maps of the Gallium element: (a) in the FEZ showing the enrichment of the grain boundaries and of the $A l 3 Z$ r precipitates. $(b)$ in the $C Z$ for comparison. 


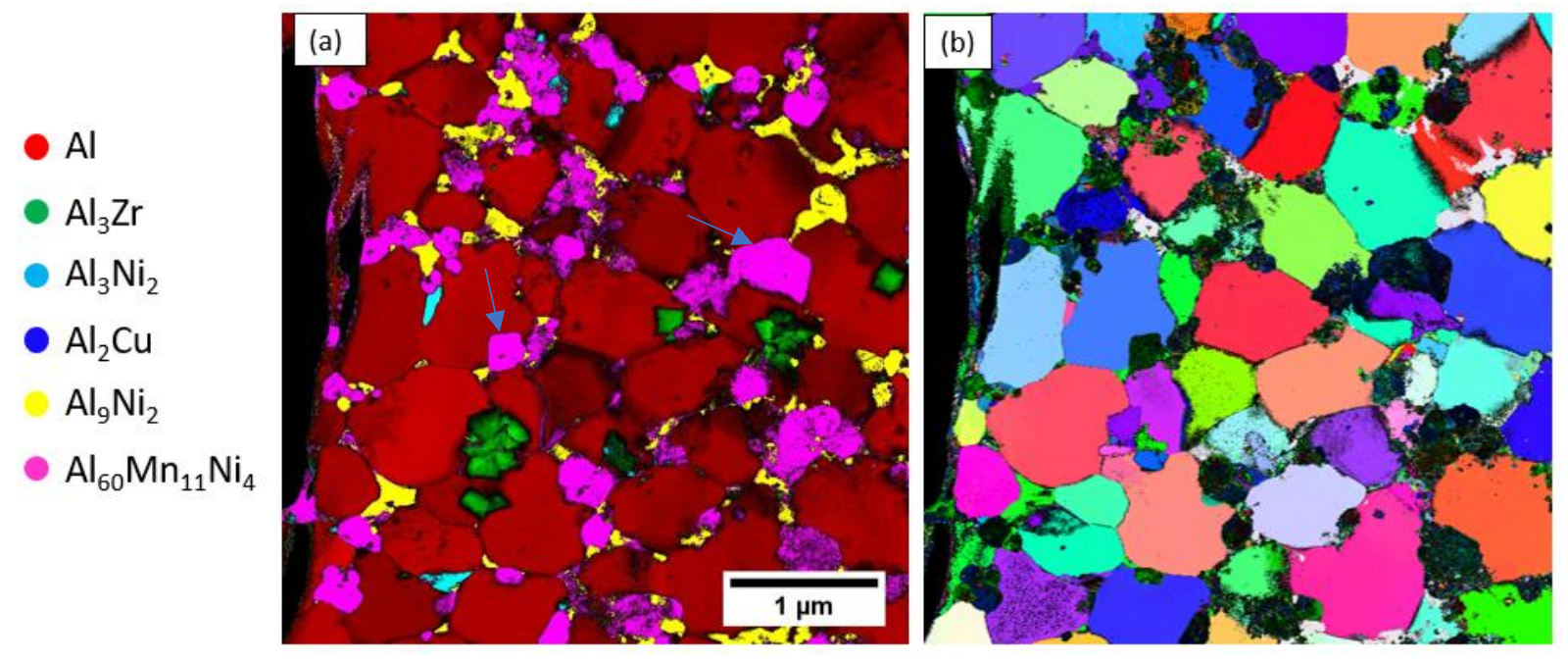

Figure S5: (a) Phase map of another region of interest in the FEZ acquired in a TEM sample prepared by electro-polishing. (b) Crystallographic orientation map (IPF) of the FCC-Al matrix in the same region shown in (a).
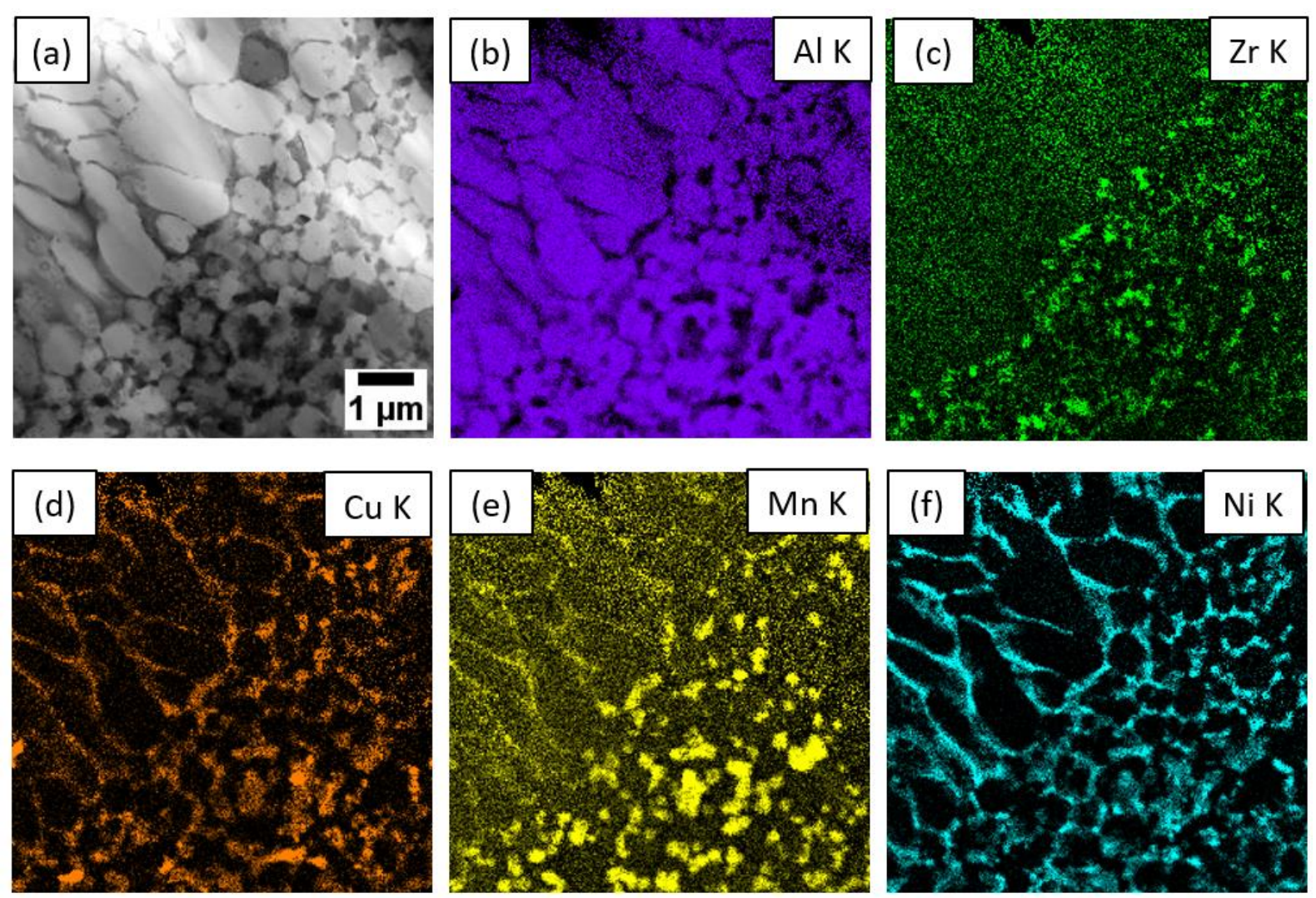

Figure S6: Distribution of the different alloying elements at the FEZ/CZ interface measured by EDS. (a) Bright Field image of the region of interest. EDS maps for the different alloying elements: (b) Aluminium (c) Zirconium (d) Copper (e) Manganese and (f) Nickel. 